\title{
The Application of Terrestrial LiDAR for Geohazard Mapping, Monitoring and Modelling in the British Geological Survey
}

\author{
Lee Jones * (i) and Peter Hobbs
}

check for updates

Citation: Jones, L.; Hobbs, P. The Application of Terrestrial LiDAR for Geohazard Mapping, Monitoring and Modelling in the British Geological Survey. Remote Sens. 2021, 13, 395. https://doi.org/10.3390/rs13030395

Received: 30 November 2020

Accepted: 15 January 2021

Published: 23 January 2021

Publisher's Note: MDPI stays neutral with regard to jurisdictional claims in published maps and institutional affiliations.

Copyright: (c) 2021 by the authors. Licensee MDPI, Basel, Switzerland. This article is an open access article distributed under the terms and conditions of the Creative Commons Attribution (CC BY) license (https:// creativecommons.org/licenses/by/ $4.0 /)$
Multihazards and Resilience Challenge, British Geological Survey, Nottingham NG12 5GG, UK; prnh@bgs.ac.uk * Correspondence: ldjon@bgs.ac.uk; Tel.: +44-0115-936-3322

\begin{abstract}
Geomatics is the discipline of electronically gathering, storing, processing, and delivering spatially related digital information; it continues to be one of the fastest expanding global markets, driven by technology. The British Geological Survey (BGS) geomatics capabilities have been utilized in a variety of scientific studies such as the monitoring of actively growing volcanic lava domes and rapidly retreating glaciers; coastal erosion and platform evolution; inland and coastal landslide modelling; mapping of geological structures and fault boundaries; rock stability and subsidence feature analysis, and geo-conservation. In 2000, the BGS became the first organization outside the mining industry to use Terrestrial LiDAR Scanning (TLS) as a tool for measuring change; paired with a Global Navigation Satellite System (GNSS), BGS were able to measure, monitor, and model geomorphological features of landslides in the United Kingdom (UK) digitally. Many technologies are used by the BGS to monitor the earth, employed on satellites, airplanes, drones, and groundbased equipment, in both research and commercial settings to carry out mapping, monitoring, and modelling of earth surfaces and processes. Outside BGS, these technologies are used for close-range, high-accuracy applications such as bridge and dam monitoring, crime and accident scene analysis, forest canopy and biomass measurements and military applications.
\end{abstract}

Keywords: terrestrial LiDAR; geohazards; mapping; monitoring; modelling

\section{Introduction}

Geomatics is defined in the International Organization for Standardization (ISO/TC 211) series of standards [1] as the discipline concerned with the collection, distribution, storage, analysis, processing, and presentation of geographic data or geographic information. This broad term applies to both science and technology, and integrates the more specific disciplines and technologies of geodesy, surveying, mapping, positioning, navigation, cartography, remote sensing, photogrammetry, and geographic information systems. The discipline of geomatics continues to be one of the fastest-expanding global markets [2]. Ground-based geomatics is driven by technology and, at present, there is a huge demand for land, hydrographic, and engineering surveyors who are able to utilize this technology fully. This is due to a high media profile, the changing nature of mapping and spatial data management worldwide, the need for faster and more accurate data gathering, and the growth in European Union and national governments' spatial data agendas and legislation. As the underpinning information provider of the land and property lifecycle, geomatics is of fundamental importance to society.

The most common geomatics applications in the British Geological Survey (BGS) use a terrestrial light detection and ranging (LiDAR) scanner (TLS) or the Pegasus Backpack mobile mapping solution (MMS) and a Global Navigation Satellite System (GNSS) in order to obtain a terrestrial equivalent of an airborne LiDAR survey and create a 3D model. Combining a terrestrial LiDAR scanner with a high-resolution digital camera and a highprecision differential GNSS enables colored point-clouds, textured triangulated surfaces, or orthophotos with depth information to be accurately geo-referenced and captured. The 
relative distance, elevation angle and azimuthal angle between the laser and the subject are measured in each scan and, once processed, a 3D surface model can be generated. From the 3D models created, a variety of products are derived including digital surface models (DSM), digital terrain models (DTM), virtual outcrop models (VOM), cross-sections, area and volume calculations, 3D photo-realistic video "fly-throughs", discontinuity maps, stratigraphic facies profiles, attributed 3D reservoir models, fossil assemblage maps, surface deformation feature recognition layers, soil erosion maps, cave surveys and change models. TLS allows geological outcrops to be digitally captured with unprecedented resolution and accuracy [3]. Structure from motion photogrammetry (SfM) has emerged as an alternative viable technology, whether deployed on an unmanned aerial vehicle (UAV) or otherwise. It is lighter, more compact, cheaper to buy and repair, and has lower power requirements than TLS. The BGS has six multi-rotor and two fixed-wing small $(<20 \mathrm{~kg})$ UAVs, which it uses to collect data for ground surface and geological investigations.

The BGS geomatics capabilities have been utilized in a variety of scientific studies [4] such as the monitoring of actively growing volcanic lava domes and rapidly retreating glaciers; coastal erosion and platform evolution; inland and coastal landslide modelling; mapping of geological structures and fault boundaries; rock stability and subsidence feature analysis; geo-conservation and public understanding of science [5]. These capabilities can be utilized alongside airborne LiDAR and other remote sensing techniques in order to provide a range of complimentary applications, or information [6]. It is clear that LiDAR scanning technology is playing an increasingly important role in the acquisition of 3D spatial environmental data worldwide. This technology and its applications are certain to develop further as the rapidity and accuracy of data acquisition, and associated monitoring and modelling capabilities, become more widely recognized. Outside the BGS, ground-based LiDAR systems are used for close-range, high-accuracy applications such as bridge and dam monitoring [7], architectural restoration, crime and accident scene analysis [8], landslide and erosion mapping, forest canopy and biomass measurements [9], mobile mapping systems, adaptive cruise control systems, manufacturing, and military applications [10].

\section{Geodetic Technology}

In 2000, the BGS became the first organization outside the mining industry to use TLS as a tool for measuring change; paired with a GNSS, BGS were able to measure, monitor and model geomorphological features of landslides in the United Kingdom (UK) digitally. Since acquisition of the first TLS, this technology has proved to be essential for the monitoring of geohazards in both the UK and overseas. The authors have $\sim 20$ years of experience in engineering surveying techniques, using TLS, GNSS and MMS. They have carried out terrestrial scanning and terrain modelling of inland and coastal landslides, eroding coastlines, actively growing volcanic lava domes, retreating glaciers, rock stability and subsidence features, soil erosion, and geo-conservation. Modern terrestrial LiDAR scanners have significantly increased the level of resolution and accuracy achievable, and the speed of data acquisition has dramatically increased, from $4 \mathrm{pts} / \mathrm{s}$ in the early days to around $2 \mathrm{M} \mathrm{pts} / \mathrm{s}$ latterly. A combination of airborne and terrestrial LiDAR can create high-resolution digital terrain models (DTM) and provide realistic 3D models of builtinfrastructure with accurate rooftops and realistic building facades. Combining these factors, with the increase in point density and accuracy achievable means that the ability to capture and measure temporal changes in geological features via repeat surveys has revolutionized ground-based geomatics research [11].

UAVs are becoming increasingly common for civilian use, with the Chinese manufacturer DJI dominating the market. They are used in such fields as surveillance [12], filmmaking [13], scientific research, surveying, disaster relief [14], law enforcement, archaeology [15], forestry and agriculture, as well as recreation. The BGS, like many other organizations, are able to utilize the usability and portability of these aircraft to create photogrammetric images and point clouds using SfM techniques, at a fraction of the cost 
of using a system mounted on an airplane. The resultant data, though not as accurate as that obtained from TLS, should still be considered more than adequate for most uses, and gives the ability to create both 2D and 3D full color models. In general, UAV results appear to underestimate the volumes of smaller features, most likely due to the reduced line of sight [16].

Radar Interferometry is another technique used in geodesy and remote sensing to generate maps of surface deformation or digital elevation. The technique can potentially measure millimeter-scale changes in deformation over spans of days to years. It has applications for geophysical monitoring of natural hazards, for example earthquakes, volcanoes and landslides, and in structural engineering, in particular monitoring of subsidence and structural stability. It can be deployed in satellites, as interferometric synthetic aperture radar (InSAR), such as the European Space Agency (ESA) launched Sentinel-1A and Sentinel 1-B, which provide global scale coverage on a 6-day repeat cycle. Alternatively, it can be ground-based, as terrestrial radar interferometry (TRI), used primarily to remotely measure the stability natural and engineered slopes, in near real-time. It can be used for a wide variety of applications, including surface mining operations, quarrying, landslides, rockfalls, glacial retreat, volcano growth, and coastal retreat, but at considerable cost.

Mobile mapping is the process of collecting geospatial data from a mobile vehicle or backpack, typically fitted with a range of GNSS, photographic, radar or LiDAR systems. These are combined with time synchronized navigation and imaging sensors. This gives the ability to survey an area as fast as you can drive, or walk.

Many publications have been written about these techniques and their relative merits and pitfalls. A comparison of the above techniques is given in Table 1, along with some useful references detailing their typical uses [11,16-23]. The table presents a synopsis of the pros and cons of each of the techniques, the times taken for data collection in the field and data processing back in the office, and some typical costs of both the hardware (purchase or hire) and software (full price and/or yearly license) that are required.

Table 1. Pros and cons of geodetic techniques.

\begin{tabular}{|c|c|c|c|c|}
\hline \multirow{2}{*}{ System } & Terrestrial & Airborne & Aerial & UAV \\
\hline & LiDAR & LiDAR & SfM & SfM \\
\hline \multirow{4}{*}{ Pros } & Long range & Very long range & Good accuracy & Good accuracy \\
\hline & $\begin{array}{l}\text { High accuracy, high } \\
\text { precision }\end{array}$ & Downward scanning & Full colour & Full colour \\
\hline & High speed data & Cover large areas & 2D \& 3D models & 2D \& 3D models \\
\hline & Built-in camera & Good accuracy & Downward looking & Down \& side looking \\
\hline \multirow{4}{*}{ Cons } & Shadow' areas & & & Pilot required \\
\hline & Dense vegetation & Very expensive & Dense vegetation & Dense vegetation \\
\hline & Severe weather & Lower accuracy & Expensive & Severe weather \\
\hline & Cloud \& fog & Downward scanning & Downward looking & Strong wind \\
\hline \multirow{3}{*}{ Data Collection } & Active Sensing & Active Sensing & Passive Sensing & Passive Sensing \\
\hline & Survey: $1 \mathrm{~h}-5+$ days & Survey: 4 h-5+ days & Survey: 4 h-5+ days & Survey: $1 \mathrm{~h}-5+$ days \\
\hline & Data: 1 day $-5+$ days & Data: 1 day-5+ days & Data: 1 day-5+ days & Data: 1 day $-5+$ days \\
\hline \multirow{2}{*}{ Typical Cost } & Hardware: £130k & Hardware: $£ 20 k$ (rental) & Hardware: $£ 20 k$ (rental) & Hardware: £5k \\
\hline & Software: $\sim £ 2.5 \mathrm{k}$ p.a. & Software: $\sim £ 10$ k p.a. & Software: $£ 3500$ & Software: $\sim £ k$ p.a. \\
\hline Reference & 11 & 18 & 19 & $16 \& 17$ \\
\hline
\end{tabular}


Table 1. Cont.

\begin{tabular}{|c|c|c|c|c|}
\hline System & $\begin{array}{l}\text { Terrestrial } \\
\text { Radar }\end{array}$ & $\begin{array}{l}\text { Satellite } \\
\text { Radar }\end{array}$ & $\begin{array}{l}\text { Backpack } \\
\text { MMS }\end{array}$ & $\begin{array}{l}\text { Vehicle } \\
\text { MMS }\end{array}$ \\
\hline \multirow{5}{*}{ Pros } & Extremely long range & Extremely long range & Scan as fast as can walk & Scan at up to $30 \mathrm{mph}$ \\
\hline & Very high accuracy & High accuracy & High accuracy & High accuracy \\
\hline & Real time, continuous & Cover laroe areas & High speed data & High speed data \\
\hline & monitoring & & acquisition & acquisition \\
\hline & Works in cloud \& fog & Works in any weather & Works inside \& outside & Built-in cameras \\
\hline \multirow{4}{*}{ Cons } & Dense vegetation & Dense vegetation & & Heavy \\
\hline & Severe weather & Expensive & Only scan where walk & Only scan where drive \\
\hline & Strong wind & Downward looking & Point density & Expensive \\
\hline & $\begin{array}{c}\text { Points must be coincident } \\
\text { Heavy }\end{array}$ & Points must be coincident & Bad weather & Severe weather \\
\hline \multirow{3}{*}{ Data Collection } & Active Sensing & Active Sensing & Active Sensing & Active Sensing \\
\hline & Survey: $1 \mathrm{~h}-5+$ days & Survey: Multiple days & Survey: $1 \mathrm{~h}-5+$ days & Survey: $1 \mathrm{~h}-5+$ days \\
\hline & Data: 1 day $-5+$ days & Data: 1 day $-5+$ days & Data: 1 day $-5+$ days & Data: 1 day $-5+$ days \\
\hline \multirow{2}{*}{ Typical Cost } & Hardware: $£ 140 \mathrm{k}$ & Hardware: Free (data) & Hardware: $£ 230 \mathrm{k}$ & Hardware: $£ 350 \mathrm{k}$ \\
\hline & Software: $\sim £ 2.5 \mathrm{k}$ p.a. & Software: $~ £ 10$ k p.a. & Software: $\sim £ 16 \mathrm{k}$ p.a. & Software: $£ 16 \mathrm{k}$ p.a. \\
\hline Reference & 20 & 21 & 22 & 23 \\
\hline
\end{tabular}

\section{Terrestrial LiDAR Scanning (TLS) outside British Geological Survey (BGS)}

In the UK, the Office of Science and Innovation identified LiDAR technology within one of eight key clusters of emerging science and technology with "the potential to...transform the delivery of public services, challenge society and/or affect wealth creation." Following this, LiDAR:net was set up to bring together a network of interested parties from academia, industry and the Natural Environ mental Research Council (NERC). Participants include the Universities of Leicester, Salford, Nottingham, Aberystwyth, Glamorgan, Loughborough, Durham, Queen's University Belfast, Infotera, 3D Laser Mapping, Halo-Photonics, Willis Research Network, Halcrow Group Ltd., Ordnance Survey, and BGS. Deliverables included the running of dedicated workshops and a scoping report to input into both the technical Earth Observation development and the NERC Technologies program.

Other major exponents of terrestrial LiDAR scanning in the UK include Geomatics Group (Environment Agency), Merrett Survey Partnership, Digital Surveys, Bluesky International Ltd., Terrain Surveys, Manchester University, and University College London.

Outside the UK, the USGS employs terrestrial LiDAR technology for a variety of projects including shoreline mapping, digital elevation and terrain mapping, dam monitoring, soil erosion, snow measurement, ground deformation and landslide mapping, flood hazard mapping and levee failure analysis, habitat mapping, and volcano monitoring. It has setup the Center for LiDAR Information Coordination and Knowledge (CLICK) in order to facilitate data access, user coordination and education. UNAVCO maintains a pool of TLS instruments and associated peripherals, digital photography equipment, software and ancillary equipment optimized to support earth science investigators. Projects include landside deformation studies in Puerto Rico, wildfire extent surveys in Colorado, volcano conduit process modelling in Utah, and biomass measurements in Florida.

European universities with ground-based geomatics departments include Z-GIS at the University of Salzburg (Austria), Delft University of Technology (Netherlands), University of Bergen (Norway) and Institut Cartografic de Catalunya (Spain). Other organizations working in terrestrial LiDAR include Laserdata (Austria), IMAO (France), SPECIM (Finland), IGI TopScan (Germany), Sineco (Italy), Artescan 3D (Portugal), Dielmo 3D (Spain), Galileo Group Inc. (USA), and Fugro.

The BGS uses Riegl and Faro terrestrial LiDAR scanners. Besides these, the major manufacturers of terrestrial LiDAR systems are Teledyne Optech (Canada), Z+F (Germany), Topcon (Japan), Leica (Switzerland), MDL (UK), and Trimble (USA). The major software companies with programs able to download and process LiDAR data include Virtalis, Golden Software, Maptek, Applied Imagery, Qcoherent, Pointools, Innovmetric, 
Blue Marble, Erdas, and Esri. Open source and free viewers are available to download, including Cloud Compare, Quick Terrain Reader, Fugro Viewer, Mars Viewer, MeshLab and LASTools.

Over the past two years, the use of TLS has increased dramatically:

- In the gaming industry, it is used to quickly and precisely render whole cities, or to recreate an accurate reproduction of a racetrack, including every undulation etc.

- The police can record the scene a car accident within a few minutes, enabling the emergency services to clear the scene, reducing traffic jams as well as preserving the evidence digitally.

- The automotive industry use TLS as a guidance system for autonomous vehicles. Near real-time processing allows the device controlling the vehicle to detect obstacles and to update its route almost instantly.

- TLS gives archaeologists the ability to create high-resolution DEMs of archaeological sites that can reveal micro-topography that may otherwise be hidden by vegetation.

- LiDAR is used in a variety of ways in meteorology including the studies of atmospheric composition, structure, clouds, and aerosols.

- In astronomy, a worldwide network of observatories uses LiDAR to measure the distance to reflectors placed on the moon, allowing the moon's position to be measured with $\mathrm{mm}$ precision.

- LiDAR allows conservation research scientists to not only measure the height of previously unmapped trees but to determine the biodiversity of the forest.

In geology and seismology a combination of aircraft-based LIDAR and GPS have evolved into an important tool for detecting faults and measuring uplift. This combination was used most famously to find the location of the Seattle Fault in Washington, USA. The USGS is using TLS more and more for land surface analysis, including the monitoring of sand dune movement and soil microtopography and erosion.

\section{Mobile Mapping}

In January 2018, the BGS became one of the first companies in the UK to purchase the Leica Pegasus Backpack, a wearable reality-capture sensor platform, combining five cameras with two LiDAR profilers and a triple band GNSS and inertial measurement unit (IMU), weighing less than $13 \mathrm{~kg}$. It is designed to be deployed quickly and easily and can be used for indoor, outdoor, or underground surveys, offering speed and portability advantages over existing terrestrial LIDAR systems, which can weigh in excess of $30 \mathrm{~kg}$ and are extremely bulky to carry. This enables the BGS to carry out 3D mapping of long coastal (or inland) sections, landslides and other unstable surfaces, ice sheets and glaciers, railway lines, roads, and other linear features. The backpack can also be vehicle mounted, for fast mobile mapping, or pole mounted, for lowering into voids or sinkholes.

Mapping underground structures has always proved to be quite difficult and complex, especially related to the issues of positioning and visibility. The Pegasus Backpack allows the user to move from an area of good GNSS coverage to one with limited or even no coverage. The BGS used this system when mapping the show caverns (old mineshafts) associated with the Heights of Abraham Park (Figure 1), with a 3D section of part of a cavern shown in Figure 2. Use of the Leica SLAM (simultaneous localization and mapping) technology and the high precision IMU ensured the achievement of accurate positioning, even during GNSS outages, and with the addition of the external light source, precise scanning of the caverns was possible. 


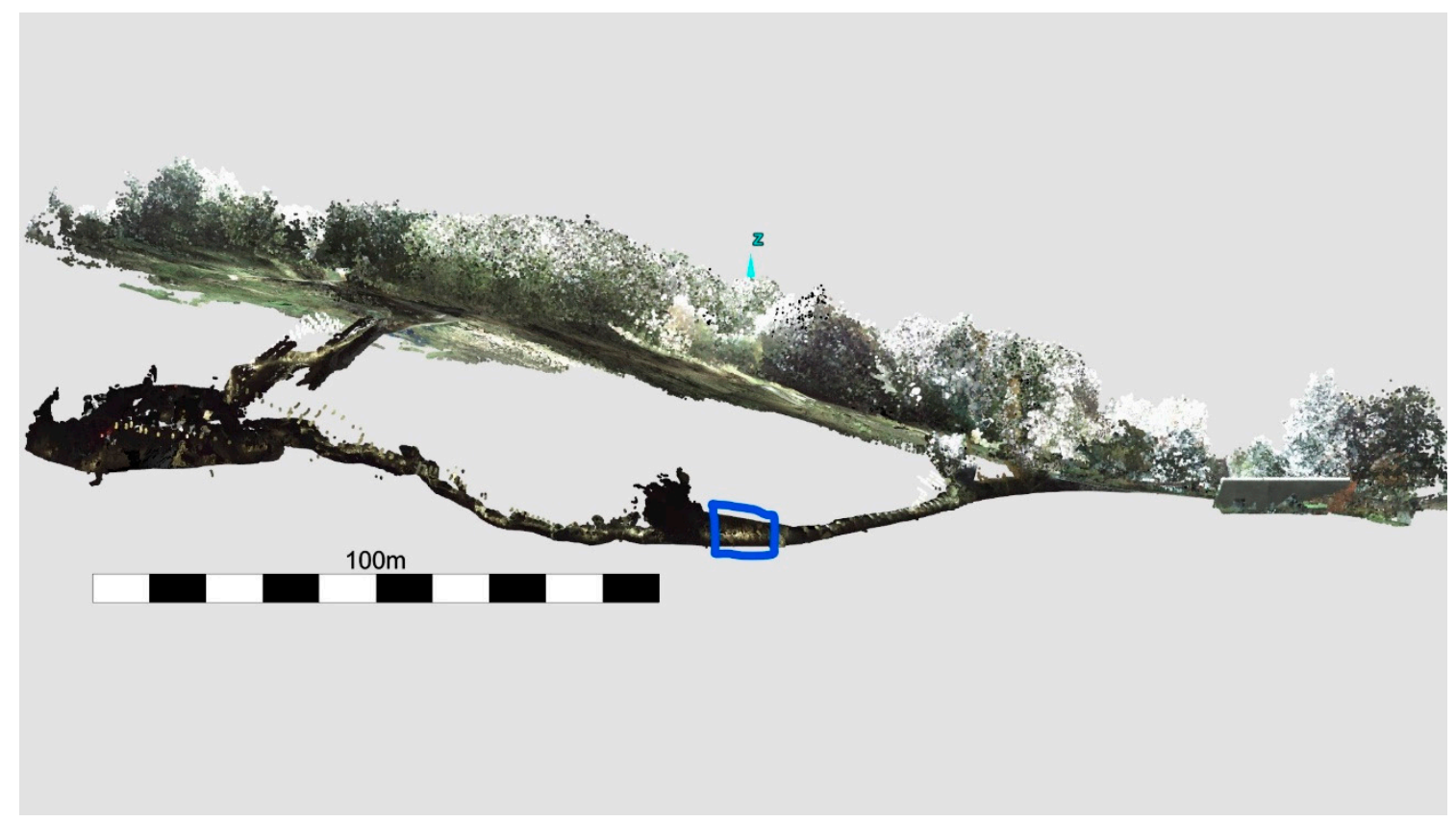

Figure 1. Elevation view of the Masson Cavern at the Heights of Abraham, Derbyshire. Blue polygon refers to close-up view in Figure 2.

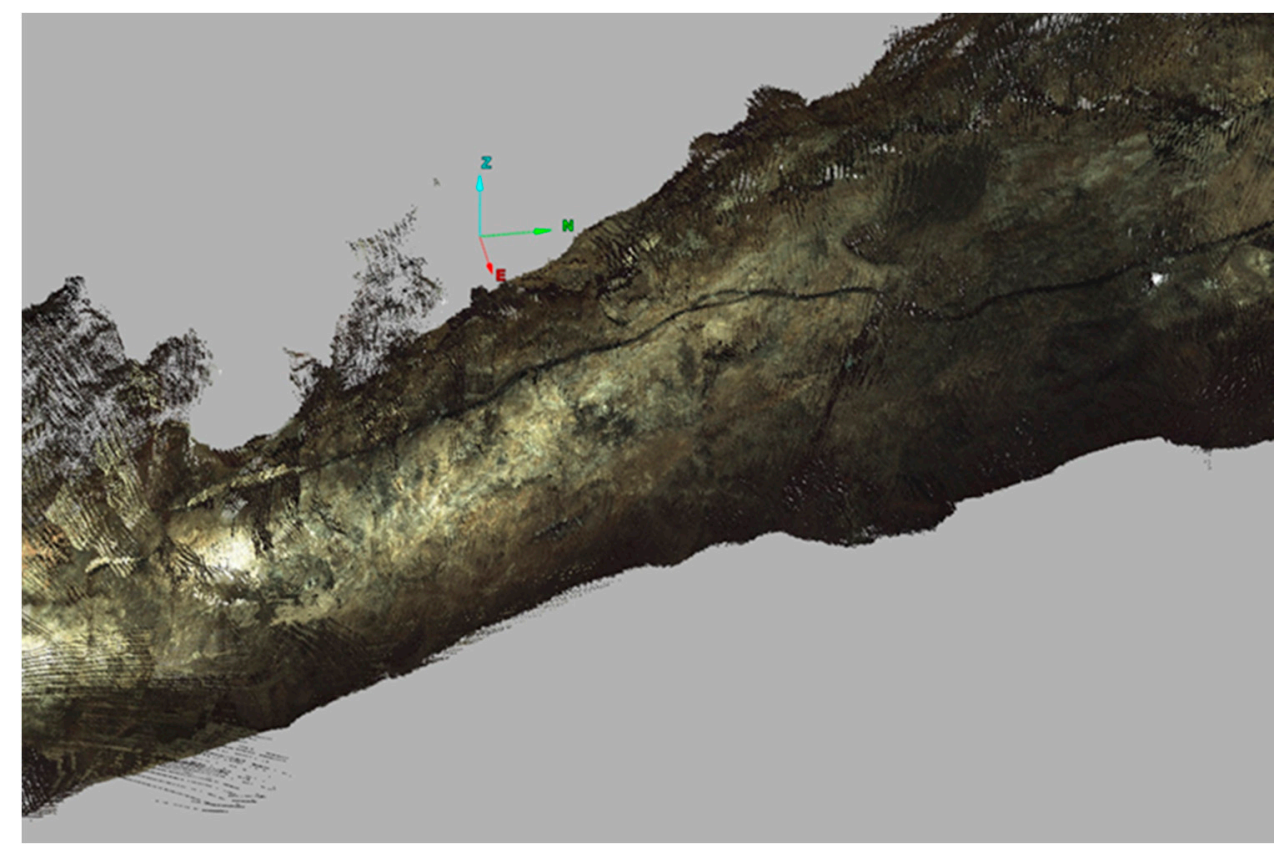

Figure 2. Close-up view of a scanned section (Blue polygon from Figure 1) of part of the Masson Cavern at the Heights of Abraham, Derbyshire.

The MMS technology has been used by BGS for many current and emerging developments in laser scanning surveys. The Pegasus Backpack has proven invaluable in many projects, such as those at Nottingham Castle (Figures 3 and 4), Tenby (Figure 5) and many others, some of which are shown in Table 2; where one Pegasus walk can cover the same area as multiple TLS set-ups. The resolution of both surveys will be equivalent, but the point density of the Pegasus will not be as great as that of the TLS survey. 


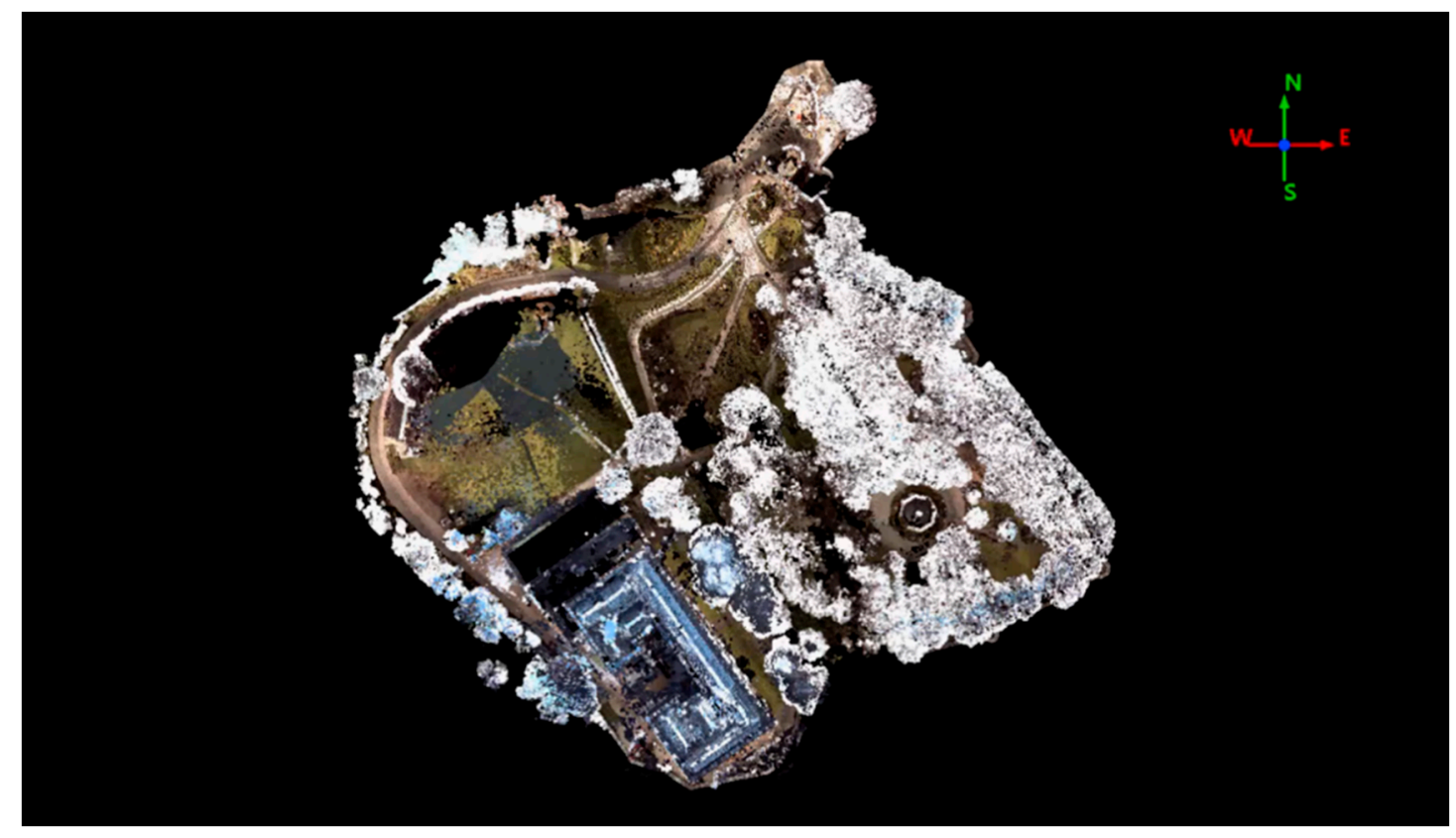

Figure 3. Plan view of Nottingham Castle and grounds, Nottingham.

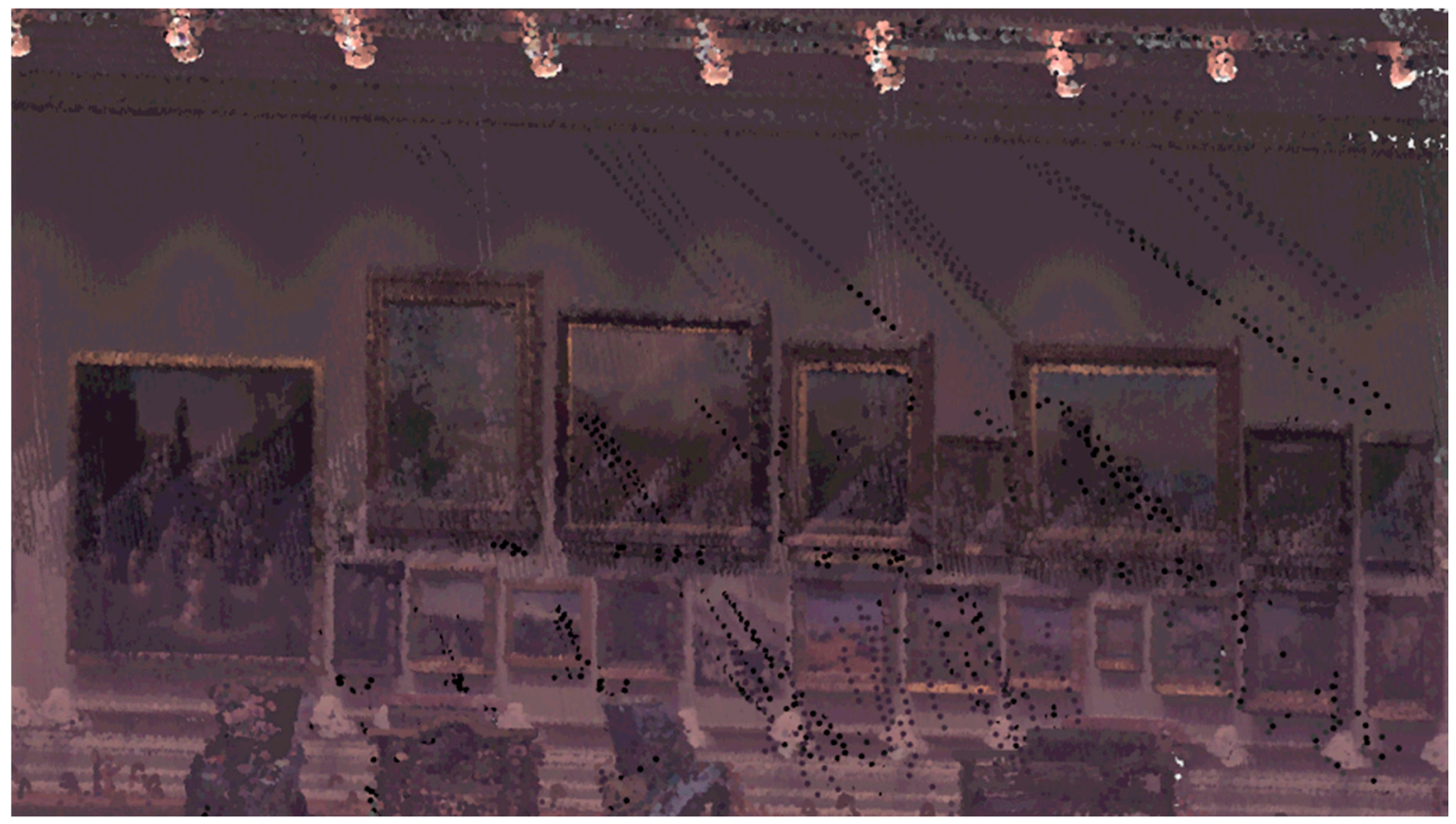

Figure 4. Inside the Long Gallery of Nottingham Castle. 


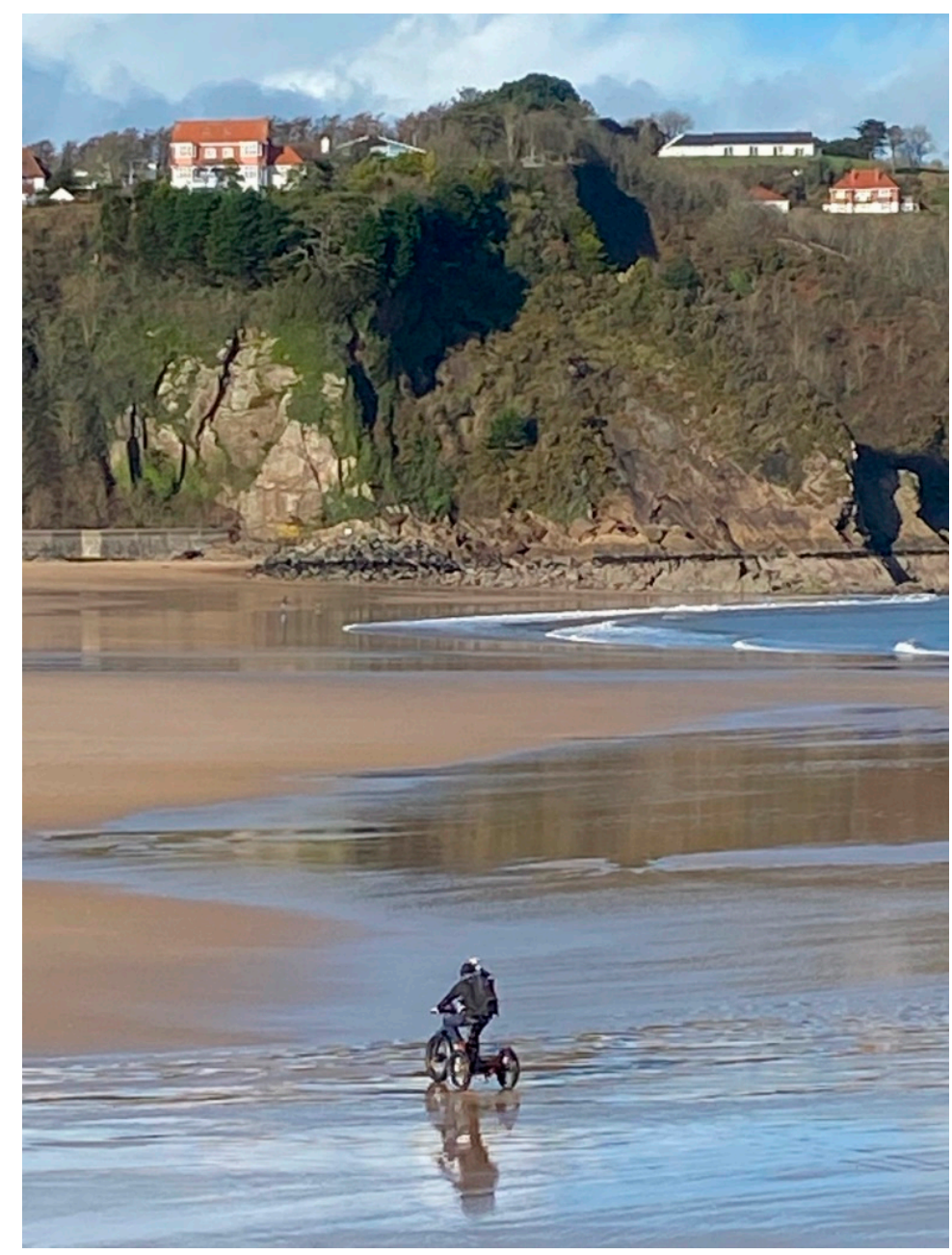

Figure 5. Pegasus Backpack mounted on an e-trike at Tenby, Wales.

Table 2. Pegasus Backpack Surveys.

\begin{tabular}{|c|c|c|c|}
\hline Project & Use & Reason & Figure \\
\hline Bacton Sandscaping Project & Initial geological modelling & $4 \mathrm{~km}$ long cliff section & \\
\hline $\begin{array}{l}\text { Hollin Hill Landslide } \\
\text { Observatory }\end{array}$ & Inland landslide monitoring & 1 Pegasus walk $=17$ TLS setups & \\
\hline $\begin{array}{l}\text { Aldbrough Coastal } \\
\text { Observatory }\end{array}$ & Coastal landslide monitoring & Extend coastal section, beach and foreland & \\
\hline Incipient Block Failure, Dover & 3D survey \& change anaylysis & $\begin{array}{l}\text { Difficult ground, requiring multiple TLS } \\
\text { setups }\end{array}$ & \\
\hline Nottingham Castle Pre-design & $\begin{array}{l}\text { Internal \& external facade } \\
\text { scans }\end{array}$ & $\begin{array}{l}\text { Impossible with any other form of laser } \\
\text { scanner }\end{array}$ & Figures 3 and 4 \\
\hline BGS Geological Walkway & Incorporation into Minecraft & 2 Pegasus walks = 12 TLS setups & \\
\hline Tenby Beach E-trike Survey & $\begin{array}{l}\text { Tidal sand volume } \\
\text { calculations }\end{array}$ & $8 \mathrm{~km}$ on E-trike only possible with Pegasus & Figure 5 \\
\hline
\end{tabular}

\section{Monitoring Change}

BGS uses its laser scanning systems to monitor actively eroding sections of coast around the UK, through frequent visits and change modelling. The techniques developed are ideal for this application as TLS is particularly suited to measuring vertical cliff sections. Due to the orientation of these sections, measurements from a plane or satellite may only be able to measure the top edge of the cliff and the platform below, whereas TLS may 
struggle with data voids on long non-linear sections. These voids are gaps, or holes, in the data usually caused by shadow areas or temporary obstructions. UAVs may offer a compromise solution; they are able to survey both the top and face of the section, albeit at a lower resolution, without any data losses. Measuring these features in the field is often very dangerous, due to tidal restrictions and slope access. These techniques enable the measurement of change in the whole cliff section, from a safe distance, and can be used to model how internal processes within the cliff slope affect coastal erosion.

The BGS Coastal Landslide Observatory, at Aldbrough, East Riding of Yorkshire, has been monitored since 2001, using a variety of GNSS, TLS, and MMS techniques [24]. The cliff faces northeast, is low $(17 \mathrm{~m})$ and of regular height. It consists of glacial till and is actively receding, both by toppling and rotational mechanisms (Figure 6). This work has shown that the cliff is eroding at a rate of up to $3 \mathrm{~m}$ per year; both landslides and the direct action of the sea crashing against it cause this erosion [25].

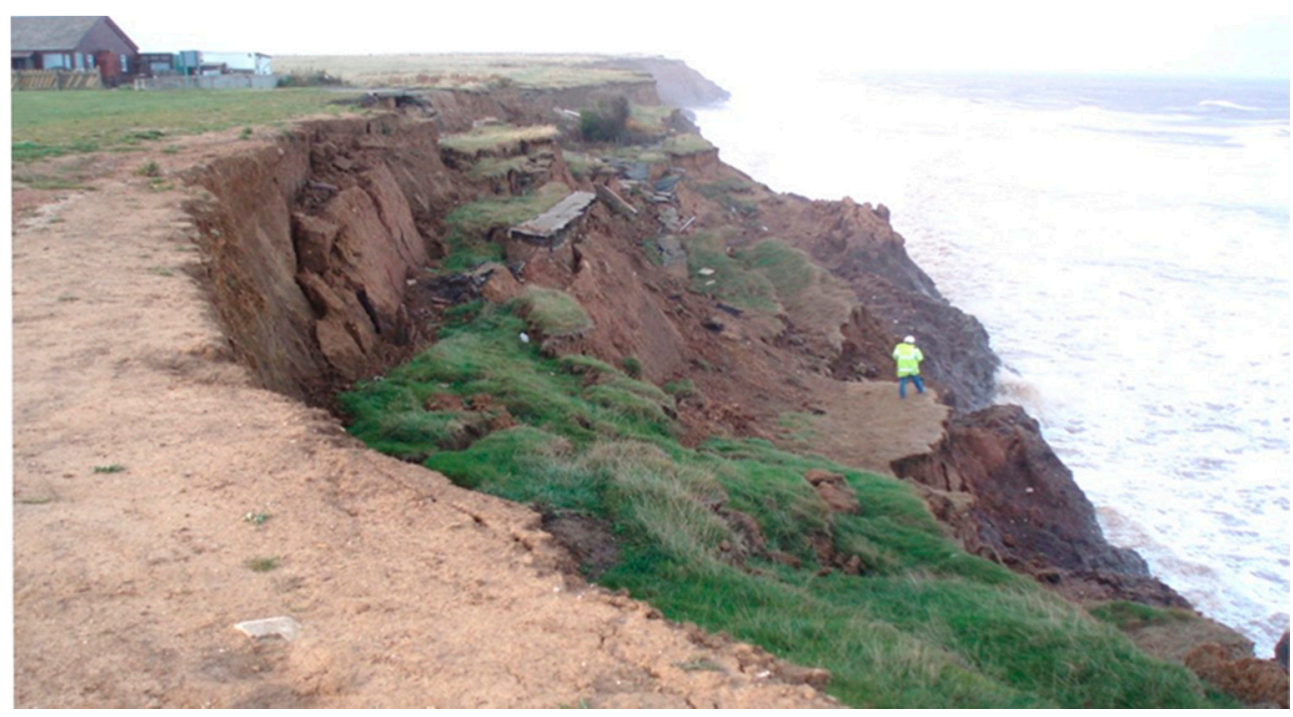

Figure 6. Rotational landsliding is the primary mechanism at Aldbrough.

Terrestrial LiDAR surveys have been carried out at the Aldbrough site over a 19-year period from 2001 to 2020 (47 surveys in total), centered on the same section of cliff and platform. The scans have varied in the area covered and [this] has necessitated clipping to an arbitrarily defined datum in order for DTM's, change models and volume calculations to be produced from them. Since 2012 the utilization of the Riegl VZ-1000, with its improved scan range of $1400 \mathrm{~m}$, accuracy of $\pm 8 \mathrm{~mm}$, measurement rate of 62,000 points/second and high-resolution digital camera, the quality and resolution of the scans and therefore the surfaces created from them has improved considerably (Figure 7). Added to this is the improvement in the acquisition and pre-processing software (RiSCANPro, Infinity), the post-processing software (I-Site Studio, Cloud Compare) and the visualization software (QT Modeler, Global Mapper, GeoVisionary) leading to improvements in the ability to visualize and quantify change more accurately and at better scales (Figure 8). The histogram in Figure 8 shows the colors associated with gain (blue) and loss (red) and also the quantity of each of these values, and where they occur within the model. 


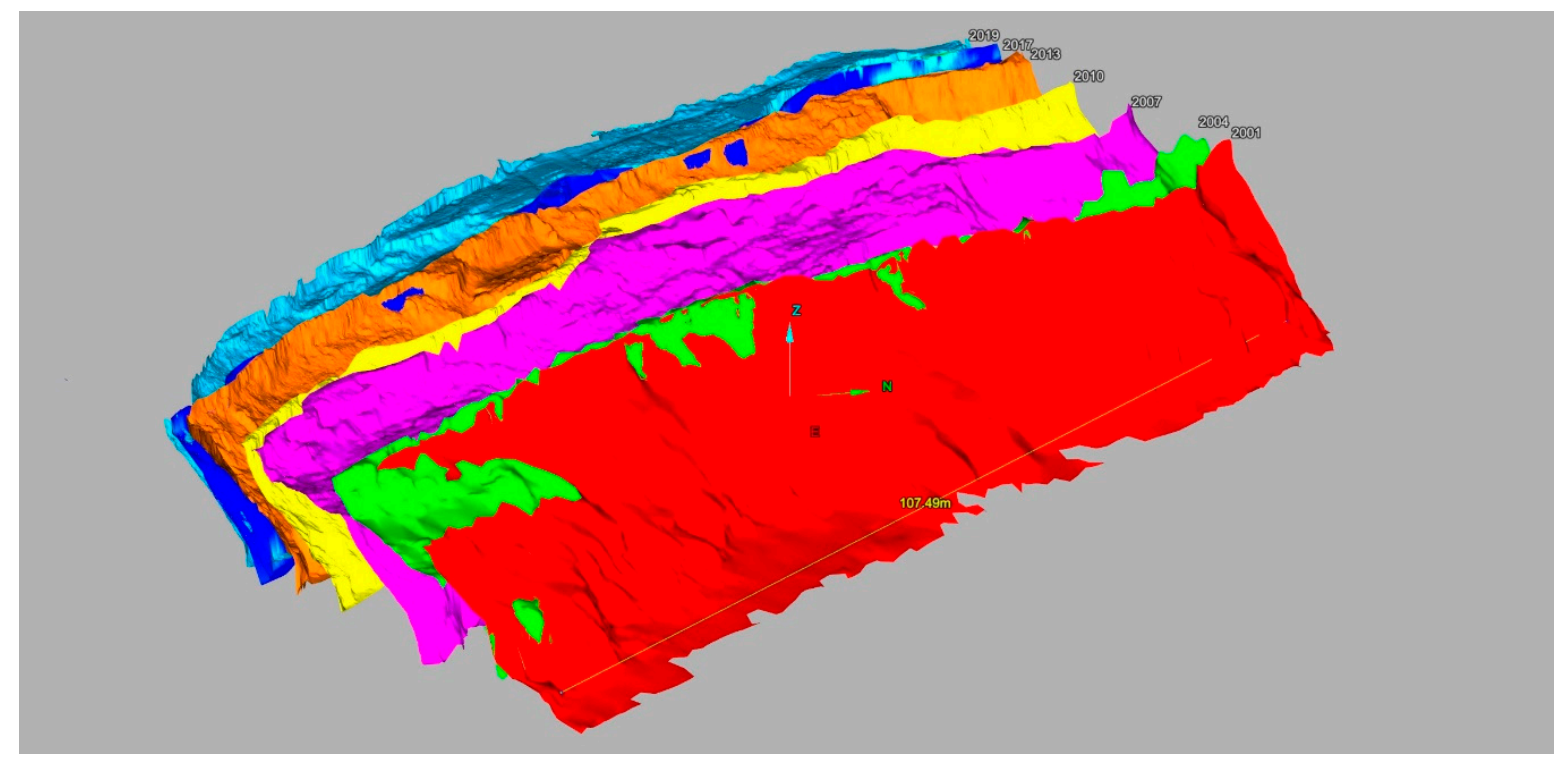

Figure 7. 3D models of the retreating cliff line at Aldbrough, 2001 to 2017.
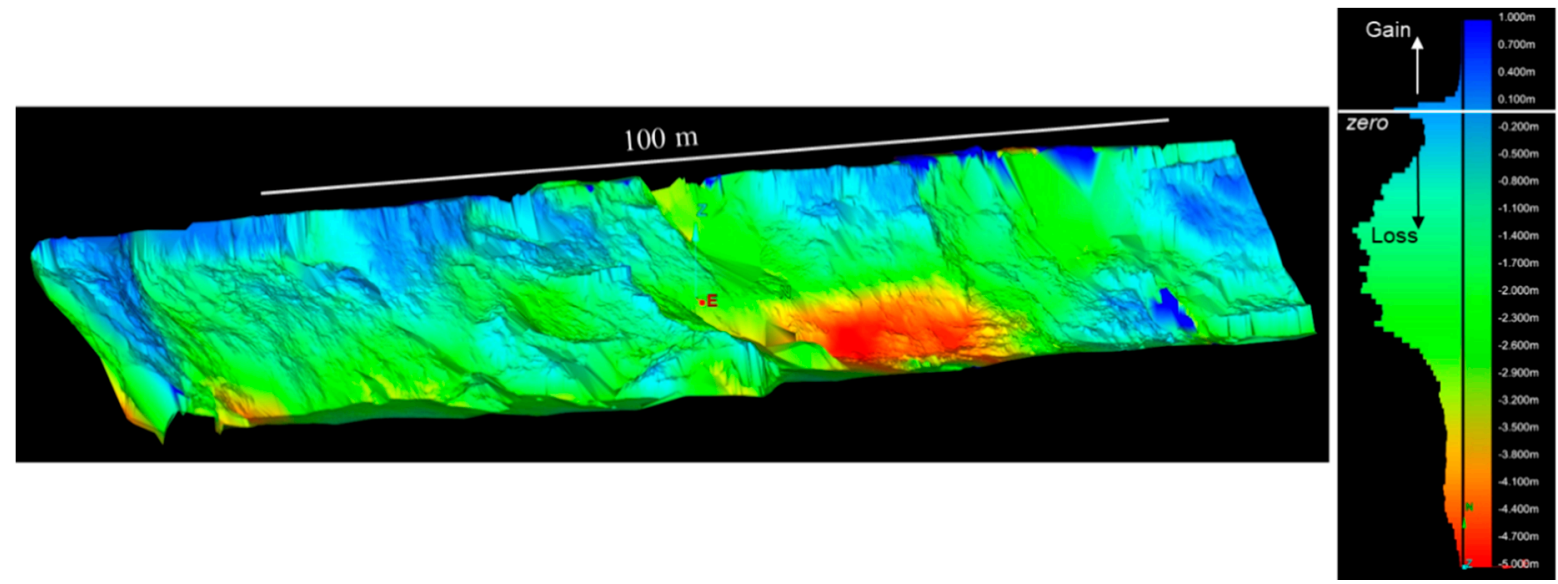

Figure 8. Aldbrough change model, colored by elevation change (February 2016-March 2017).

The BGS operate an observatory site at Virkisjökull in southeast Iceland, studying the evolution of the glacier and the surrounding landscape and their responses to regional climate change. Sensors at the site were constantly collecting climate and seismic data, on an hourly basis, over a ten year period, from 2009 to 2018. Repeated high resolution (25-40 mm accuracy) surveys were carried out annually, over the same time period, and studied how both the glacier and land surface, and the deposits beneath, changed over time. Cutting-edge technologies, not used in such a combination anywhere else in the world, were used to give unique insights into processes of landscape formation and responses of glacial systems to climate forcing. Virkisjökull and its neighbor Falljökull are retreating rapidly, like most glaciers in Iceland [26]. Since 1996, the glacier margin has retreated nearly $500 \mathrm{~m}$, and it appears that this rate has accelerated over the last five years (Figure 9). 


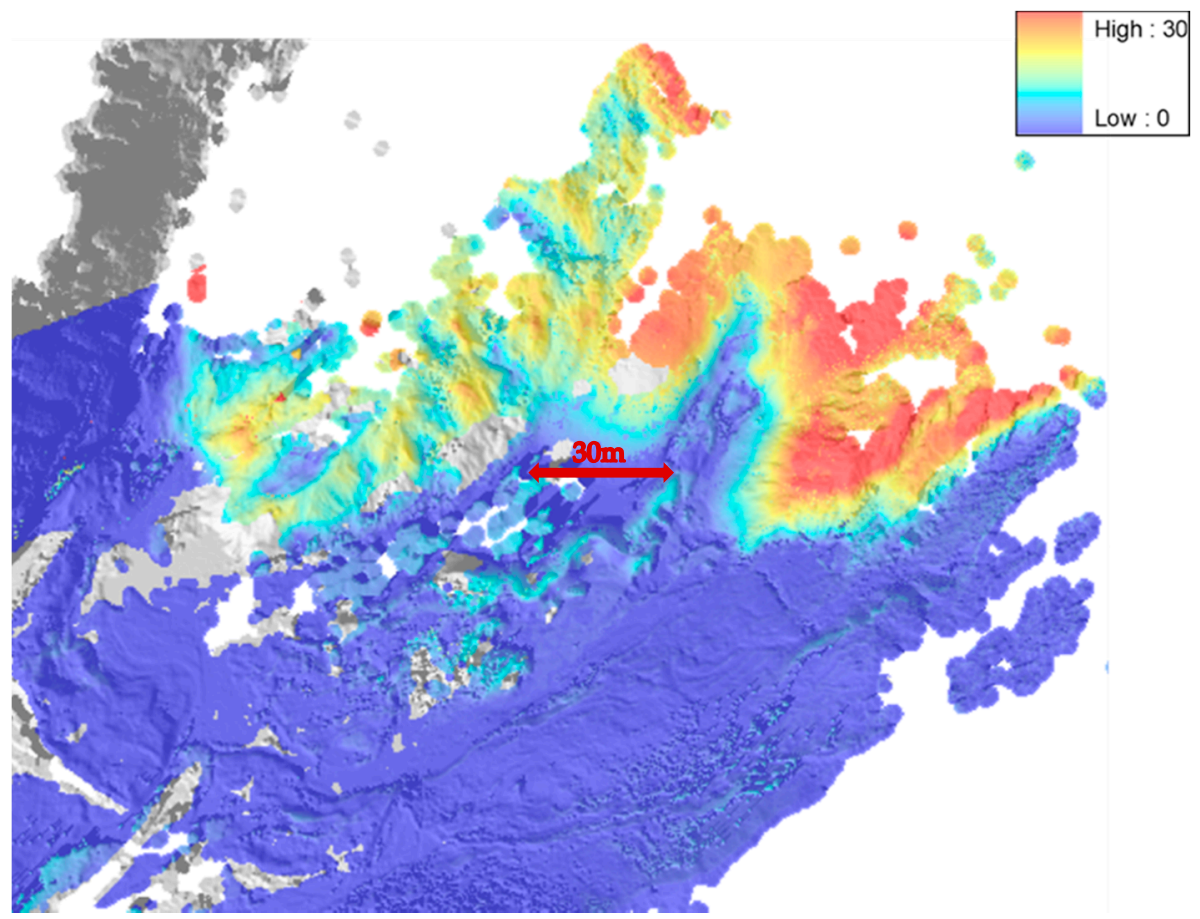

Figure 9. Falljökull glacial margin; change detection model: 2009 to 2012.

By using a combination of repeat TLS surveys, on-ice based GNSS and ground penetrating radar (GPR) the BGS have been able to see the full picture of glacial retreat for the first time (Figure 10). This unique approach allowed the TLS surveys to show changes in the glacier, glacial ice margin, and glacial foreland, whilst the GNSS stations indicated the speed and direction of glacial flow. This work has shown that the margin of the Falljökull glacier has ceased moving and is now undergoing stagnation [27]. However, field and photographic evidence shows that the icefall remains active, feeding ice from the accumulation zone on Öraefajökull to the lower reaches of the glacier. To accommodate this continued forward motion, the upper section of the glacier below the icefall is undergoing intense deformation (folding and thrusting) and, as a result, is being thrust over the lower, immobile section of Falljökull [28]. This type of behavior has never been described before and could have implications for how other steep, mountain glaciers around the world are responding to changes in the climate [29]. Because of this Falljökull glacier has been called the "zombie" glacier [30].

There can be few more hazardous situations than that of monitoring a volcanic andesite lava dome for signs of an impending collapse. Partial collapse of a lava dome generates hot, fast-moving pyroclastic density currents. Monitoring in such circumstances requires that measurements be taken from a distance that minimizes the threat from eruption and from asphyxiation by volcanic gases. The method also needs to be rapid to minimize the time spent by the monitoring team in the hazardous zone [31]. We have used TLS techniques to monitor the growth of the lava dome of the Soufrière Hills Volcano, on the Caribbean island of Montserrat (Figure 11). In May 2006, our measurements helped to identify the changes in lava dome growth rate that directly preceded a total lava dome collapse [32]. The technique utilizes multiple passes of the scanner, as the presence of volcanic gas and ash (from occasional rock falls) clouds can lead to a reduction of $10-20 \%$ in the number of scan points returned. Multiple passes increase the chance of "seeing" the dome through these drifting clouds. 


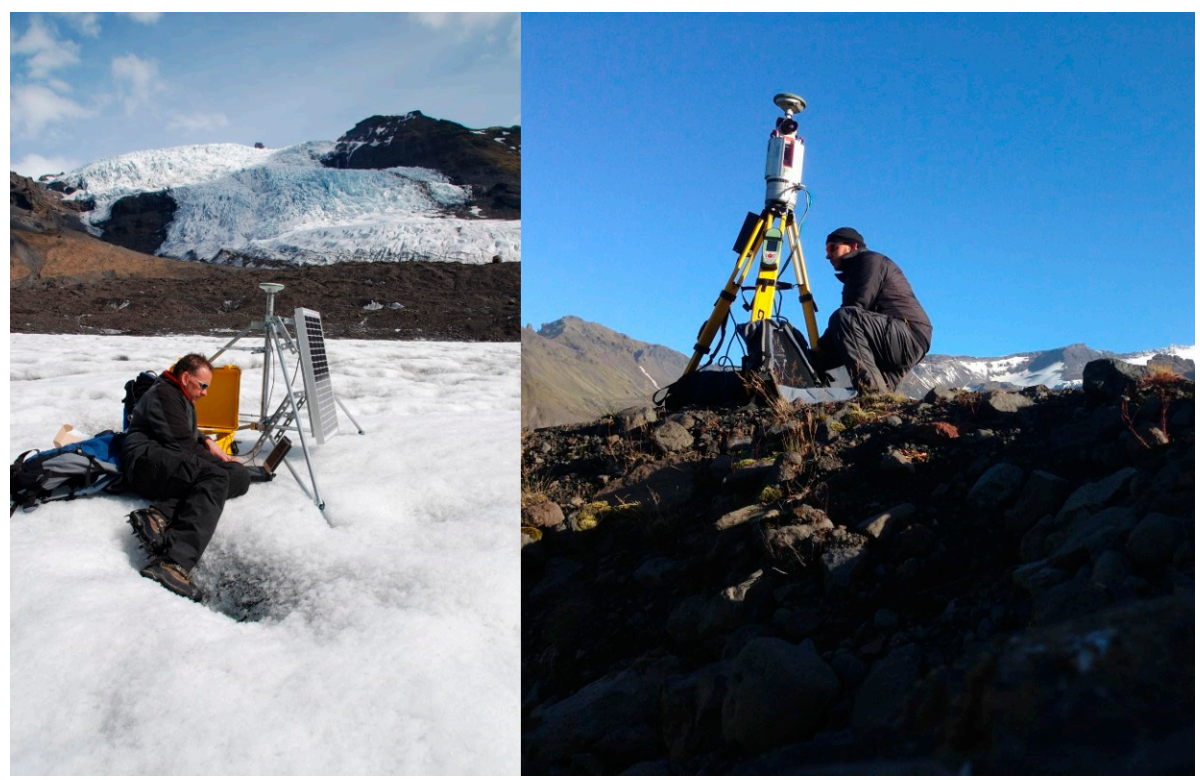

Figure 10. Data download of on-ice GNSS unit. Terrestrial LiDAR Scanning of glacial foreland, Falljökull Glacier, Iceland.

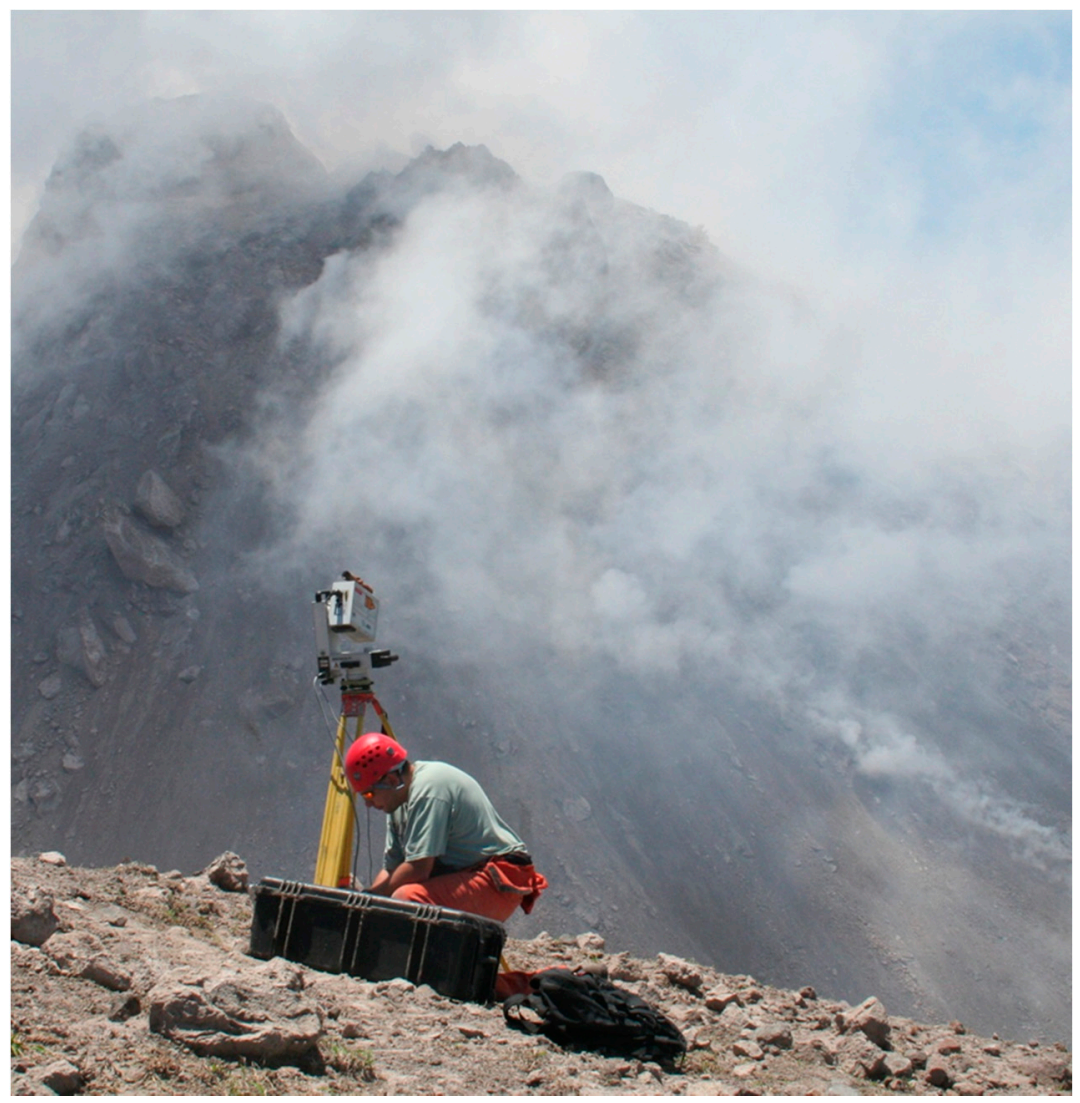

Figure 11. Scanning the active lava dome of the Soufrière Hills Volcano, Montserrat.

\section{Virtual Outcrop Modelling}

A virtual outcrop model (VOM) is a digital 3D representation of the outcrop surface, mostly in the form of a photorealistic textured polygon mesh or a point cloud with associated RGB data. 
The BGS has operated a landslide field observatory site at Hollin Hill, in North Yorkshire, since 2004 (Figure 12). It brings together a combination of field surveying, geomorphological, geophysical, engineering, and hydrogeological expertise at BGS. The landslide is several hundred meters wide and extends some $200 \mathrm{~m}$ down slope. It is located on the south facing side of a degraded Devensian ice-margin drainage channel; the slope has an angle of approximately $12^{\circ}$.

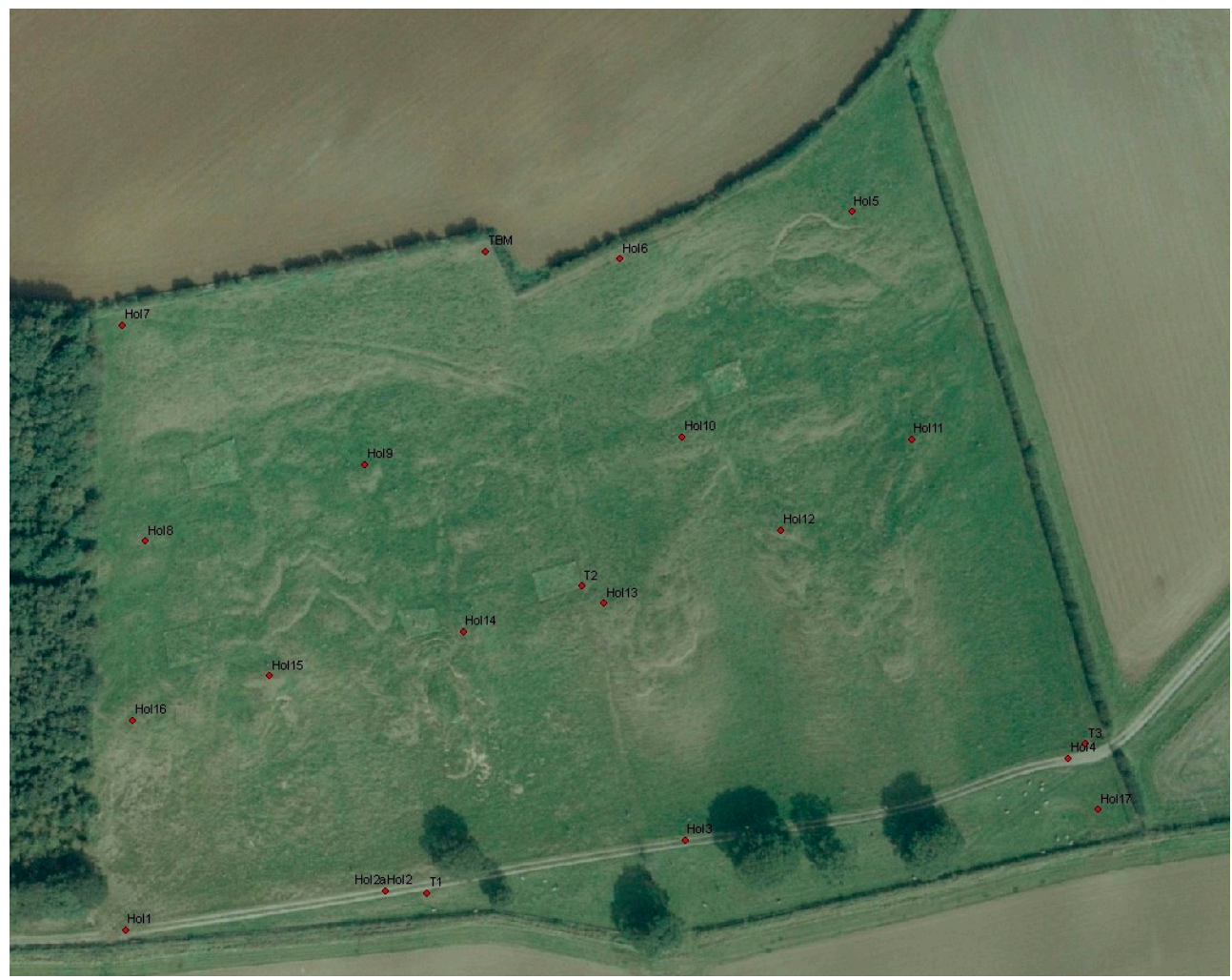

Figure 12. Aerial photograph of the Hollin Hill landslide; fence boundaries show lateral landslide extent.

The "complex" landslide is largely caused by the movement of the Whitby Mudstone Formation, which is highly prone to landsliding. The landslide is characterized by shallow rotational failures at the top of the slope in the Whitby Mudstone, which move through an area of translational landslide movement and "cascade" over the in situ Staithes Sandstone Formation feeding into four larger-scale slow-moving (i.e., tens of centimeters per year) lobes of slumped material at the bottom of the slope [33]. Relatively little is known about the hydrogeology of the site. However, a spring line extends across the base of the slope where the Staithes Sandstone overlies the underlying Redcar Mudstone Formation (Figure 13). Figure 14 shows a stylized model (not to scale) of the solid geology and slip surface of the landslide. 


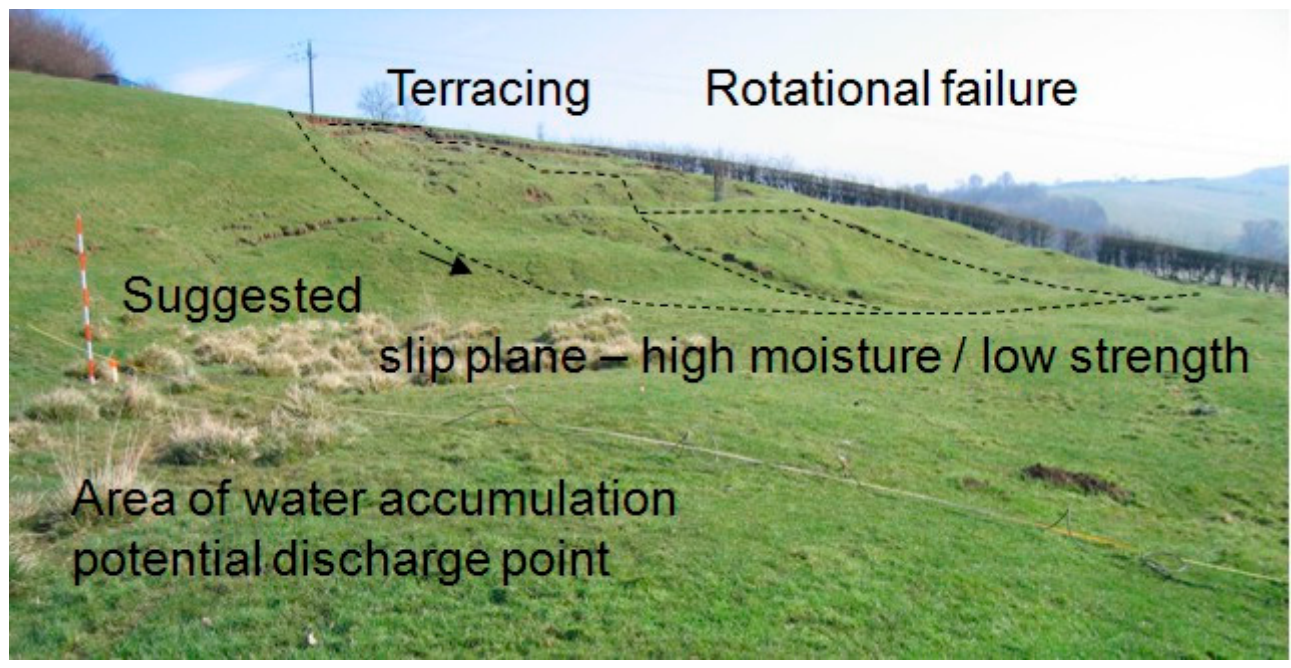

Figure 13. Annotated photograph of the Hollin Hill landslide.

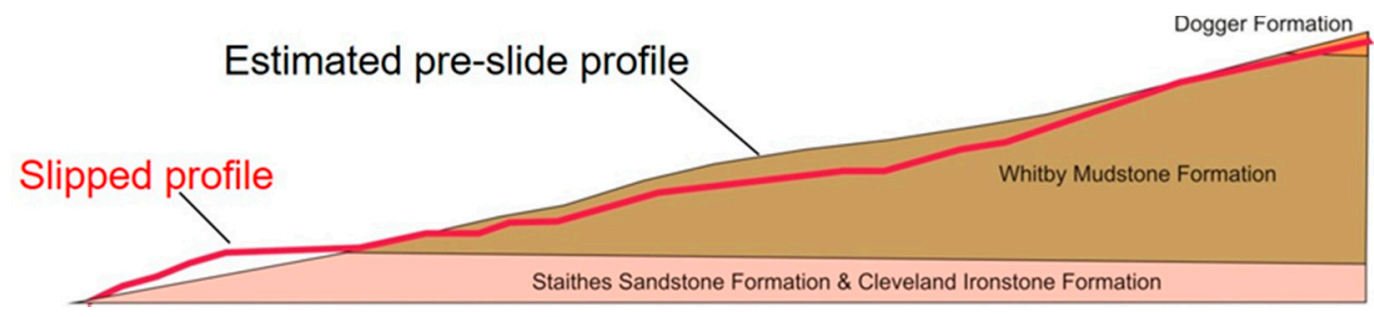

Figure 14. Solid Geology model of the Hollin Hill landslide (not to scale).

Both aerial and terrestrial LiDAR surveys have been carried out at this site. These have provided geologists at BGS with the opportunity to study the different technologies for monitoring an active slow-moving landslide site in the UK. The initial method of survey is long-range laser scanning. The first (baseline) survey records the ground surface of the landslide and surrounding area in three-dimensions (Figure 15). Subsequent surveys of this active landslide record the movement of the slope. Surveys are carried out at six-monthly intervals, the data collected in the field by LiDAR, and GPS are entered into computermodelling packages. The results are processed to provide data to model the way in which the landslide is moving. Information obtained by the Terrestrial LiDAR survey will allow us to monitor the changing shape of the surface and create change models between visits (Figure 16).

Since 2018, the landslide has been monitored using the Leica Pegasus backpack mobile mapping solution, enabling digital terrain and surface models (DTM, DSM) to be created in a shorter time, and changes to be assessed (Figure 17). The use of MMS on this slope means that the shadow areas that are potentially present when using TLS are eliminated. However, the point density, and therefore the overall resolution, is lower and issues do arise where the vegetation becomes dense. 


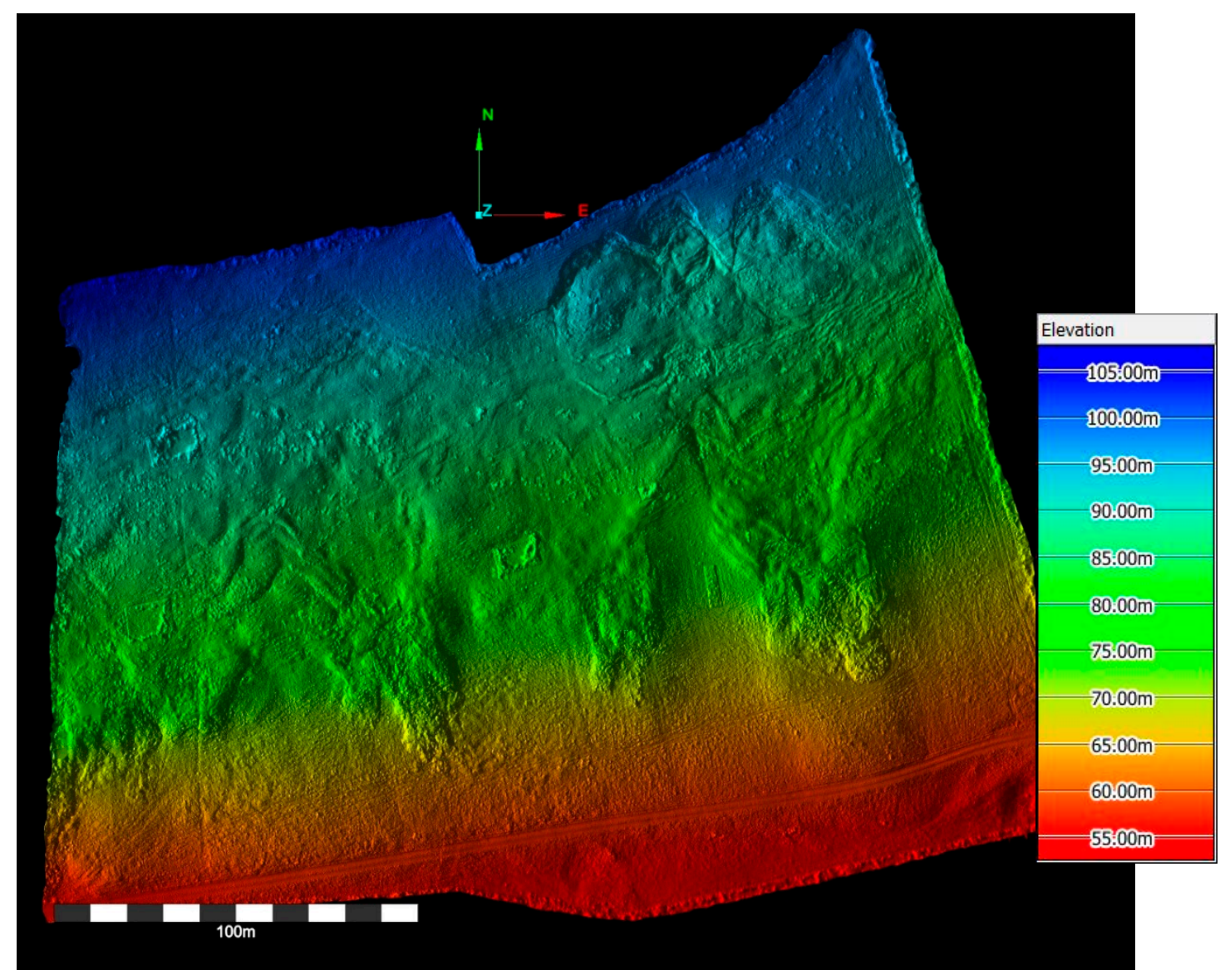

Figure 15. Elevation model of initial TLS survey of the Hollin Hill landslide.

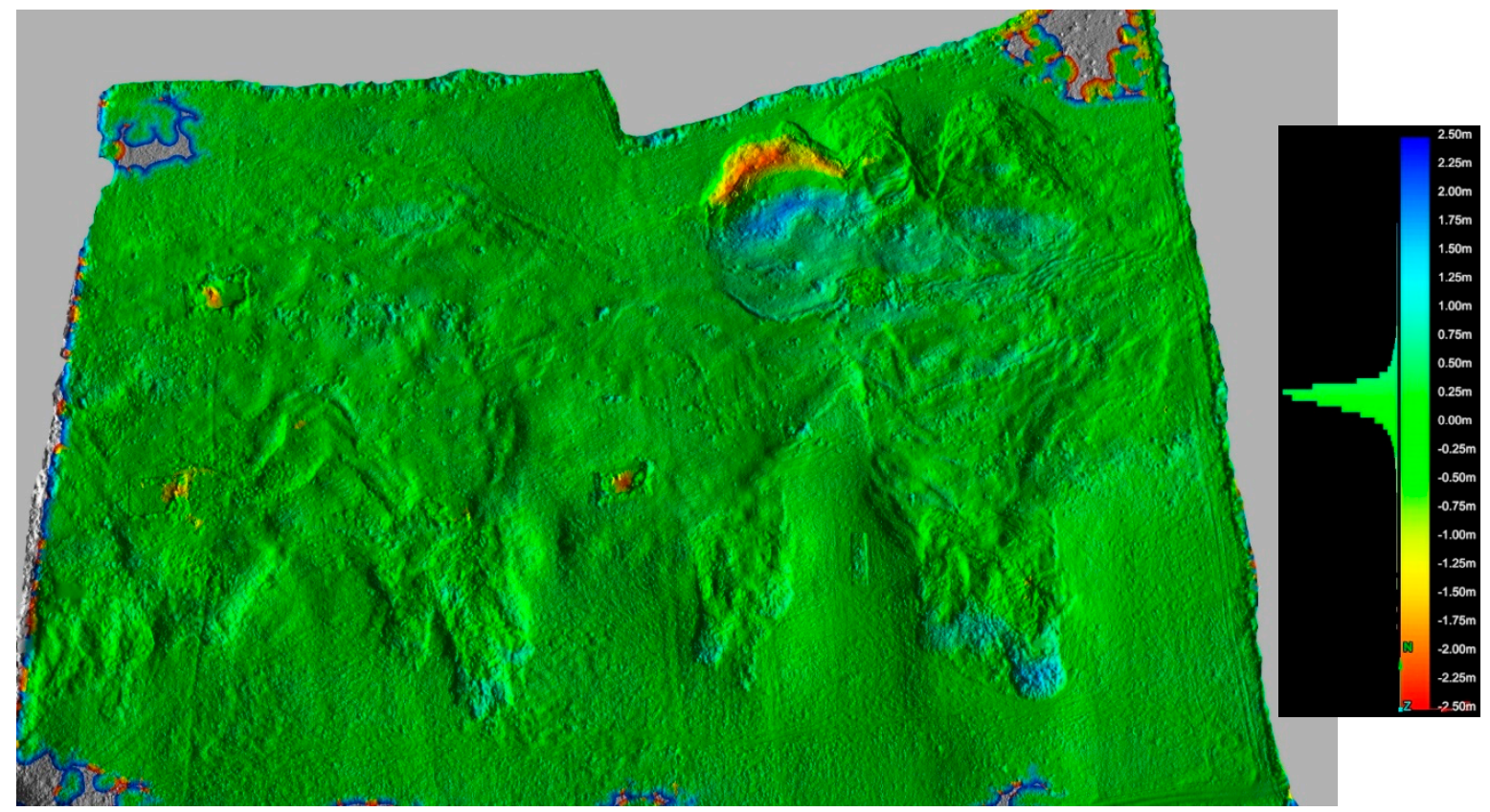

Figure 16. Hollin Hill landslide Change model (2008-2018). Red -2.5 m, Blue +2.5 m. 


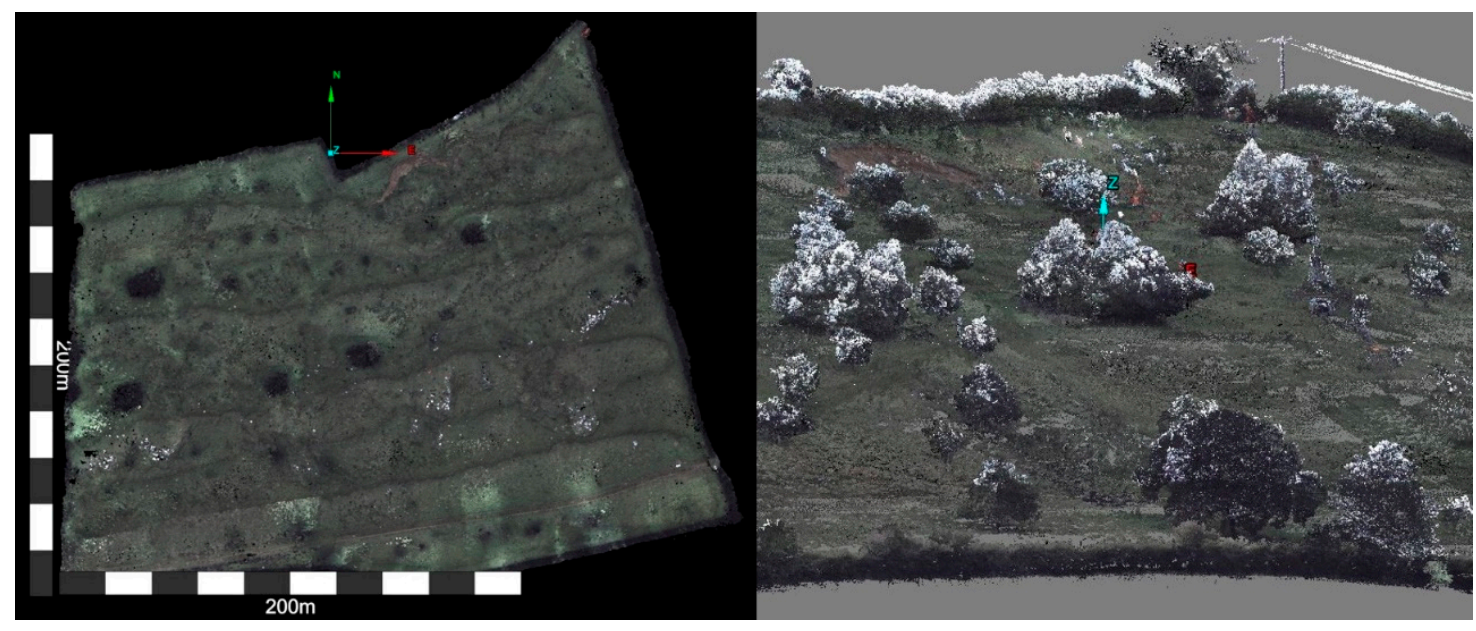

Figure 17. Digital terrain (DTM) and surface (DSM) models of the Hollin Hill landslide.

The Seven Sisters, in East Sussex, is a $4 \mathrm{~km}$ long and approximately $75 \mathrm{~m}$ high series of eight cliffs between Seaford and Eastbourne (Figure 18). As part of a larger BGS research project into the distribution of flint beds and their relative positions across the Chalk, TLS was carried out along the full length of the Seven Sisters site. TLS provided the optimum solution to the problem of measuring the extent and distance between the Flint bands in such a large cliff, which cannot be reached directly. Due to the tidal range, and the need to work at a safe distance from the cliffs, the Riegl VZ-1000 TLS was used to carry out the survey. The work took three days to carry out and was able to provide geologists with extremely detailed ( $25 \mathrm{~mm}$ accuracy) scans of the full section, in both true RGB color and intensity (Figure 19), the latter of which provides a more noticeable way to view the much darker flint beds, and therefore map them more easily.

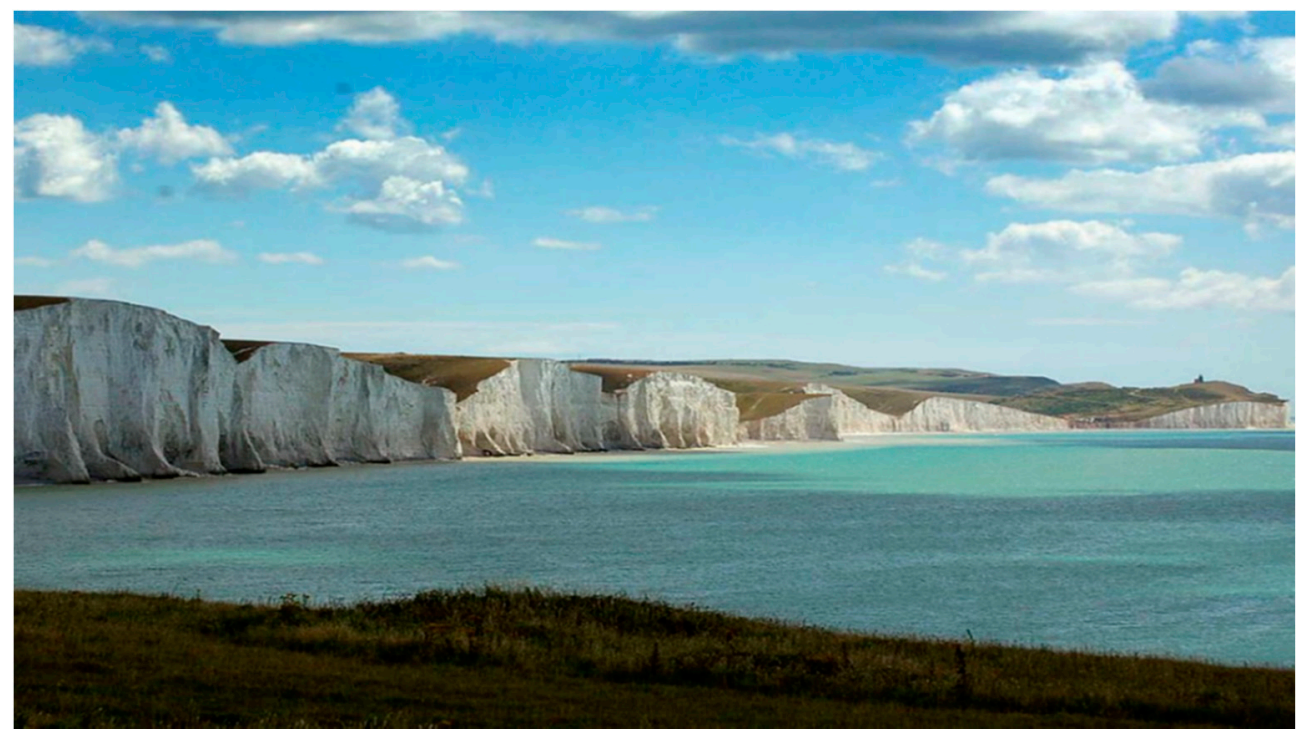

Figure 18. Seven Sisters cliff, East Sussex (4 km long $\times 75 \mathrm{~m}$ high). 


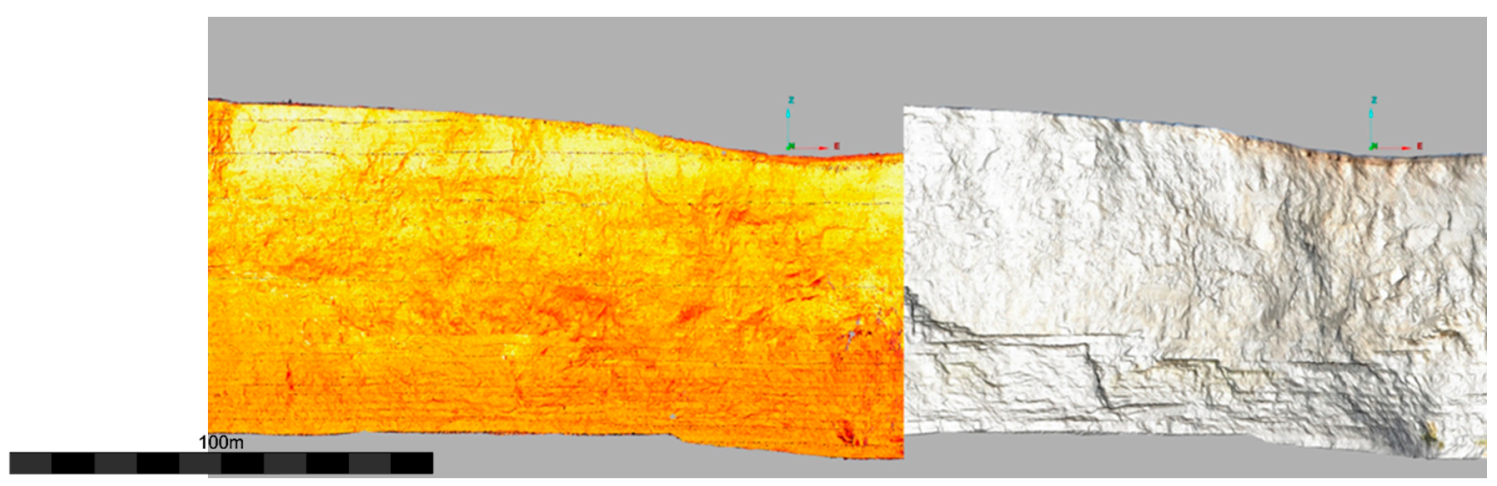

Figure 19. Intensity and RGB color scans of a section of the Seven Sisters cliff.

The main objectives of the BGS Permian Sandstone study, in the Eden Valley, are to undertake discontinuity analysis using LiDAR scans and to provide high-quality 3D images for further stratigraphical study (particularly where outcrops are inaccessible). The study also links with the Permo-Trias Cross-Cutting Project, to provide detailed geological information to assess the suitability of Permian and Triassic strata for carbon sequestration and to create 3D property models for flow modelling of $\mathrm{CO}_{2}$. Locations of potentially suitable sandstone outcrops were identified by interrogating several BGS data sets, and following consultation with hydrogeological and mineralogical colleagues six outcrops were scanned in the Eden Valley.

The RGB colored LiDAR scans were used in order to create DTMs and virtual outcrop models (VOM's) of the outcrops (Figure 20). In turn, these models were used to create 3D S-Grid facies models (in SKUA-GOCAD) to be used for $\mathrm{CO}_{2}$ flow modelling, as part of research into carbon capture and storage in sandstone reservoirs (Figure 21). These models provide important sub-seismic scale information about geological heterogeneity for flow simulations.

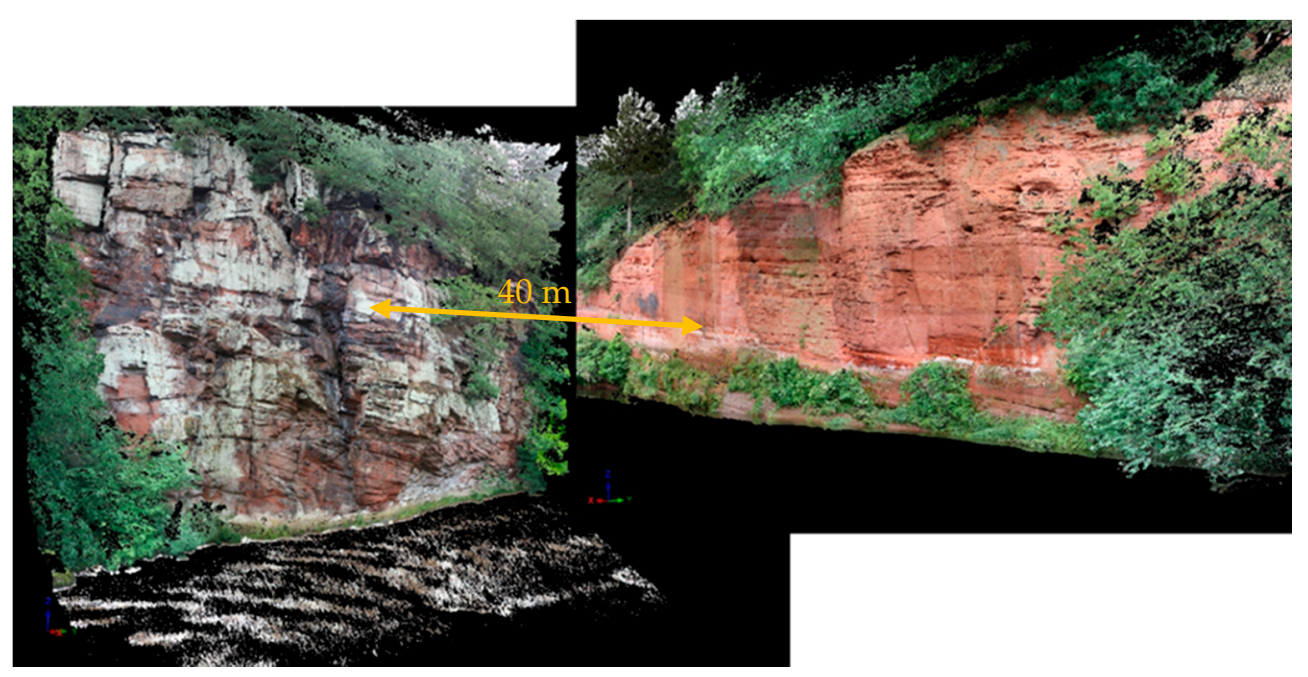

Figure 20. Virtual outcrop models of Eden Valley outcrop. 


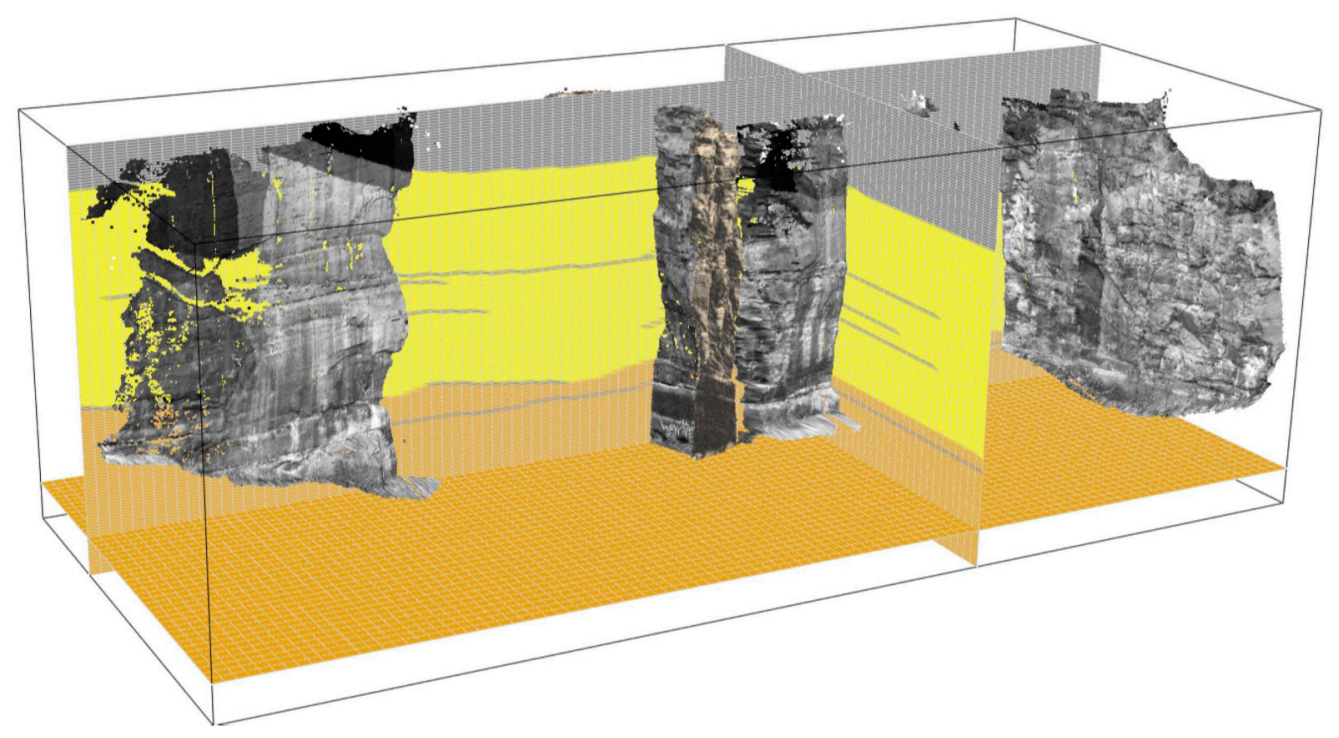

Figure 21. 3D attributed S-Grid generated from VOM.

\section{Discussion}

The BGS is currently at the forefront of TLS and MMS based research for geohazard mapping, monitoring, and modelling, with over 400 surveys from 200 sites, both in the UK and overseas, carried out over a 20-year period. During this time, the BGS has utilized these technologies for widespread applications in earth sciences, engineering geology, geohazards, and climate change, including terrain modelling of inland and coastal landslides, eroding coastlines, actively growing volcanic lava domes, retreating glaciers, rock stability and subsidence features, soil erosion, and geo-conservation. The BGS also has a long history of overseas work in geodetic monitoring, using satellite and airborne radar and LiDAR and, more recently, using photogrammetric techniques in UAVs.

Examples of these projects can be found at: https:/ / www.bgs.ac.uk/geology-projects/ geomatic-surveys/. Besides these, we believe that TLS and other associated techniques can be applied to the following applications:

- Use of TLS to generate digital models of historic buildings, geological outcrops, or other structures for geo-conservation, geo-tourism, and distance learning.

- Combine TLS with multi-spectral imaging cameras in order to create virtual outcrop models (VOM) of geological structures.

- Use TLS to detect cracks and wet spots in the clay-lined caps of landfill sites, particularly with respect to "closed" landfills.

- Use TLS to monitor long-term ground movement due to shrink-swell clays, compressible soils or Karst as a ground-truthing procedure for InSAR techniques.

- Use TLS to "join-up" fractures and faults in outcrops. The structures of one side of the outcrop can be measured and then the other side (inside, if a cave etc.) and a virtual model can be created of the two parts.

- Use TLS to measure the loss of glacial volume. This could be compared to the volume of water flowing out of the glacial lake (during the same time interval). This would give us the total runoff volume that was accounted for by net change in glacier snout storage over time.

- Use of TLS for 3D mapping of temporary exposures, made by excavations, blasting, mass movements (landslides etc.), or even trial pits.

- Use of TLS to study coastal evolution, in order to determine the changes in beach thickness over time.

- Use of TLS to monitor pre-cursor displacement failures in cuttings or embankments.

- Use of TLS to complement and calibrate the outputs of digital aerial photogrammetry. 
- Use of the Pegasus Backpack allows building information modelling (BIM) using both imagery and point cloud data to document outdoor, indoor, and even underground areas to be carried out.

- Use of InSAR to calculate long-term and future effects of coastal retreat in low-lying areas, or glacial retreat, on a local, national, or global scale.

- Use of InSAR to calculate potential subsidence rates due to natural subsidence.

- Use of UAVs in tandem (or more) to cover medium-large areas of land simultaneously, making surveys quicker.

- Use of UAV incorporating blue/green LiDAR to look at near-shore and inland water sources to determine depth and structure of bed.

\section{Conclusions}

The developments in, and applications of, terrestrial LiDAR at BGS in the last two decades have demonstrated the wide capability of this and related techniques in the field; some examples of which have been described in this paper. Advances in technology have meant that the applications of terrestrial LiDAR in the field of engineering geology have expanded dramatically over this time period. For example, use of the Pegasus Backpack has demonstrated that disaster responders will be able to capture data in 3D, on foot, in danger zone areas; and, in combination with SLAM and IMU, achieves accurate positioning even during GNSS outages. With the addition of the external light-source precise scanning of tunnels and cave systems is also possible. The Pegasus Backpack can also be vehicle mounted, for mobile mapping of large areas, or pole mounted, for lowering into voids or sinkholes. Current GNSS units operate to sub-centimeter accuracy, and can be used to acquire accurate surveys of non-linear features, including watercourses where the depth to the bed cannot be recorded as easily as other features. The ability to combine different technologies (LiDAR, GNSS, UAV, InSAR) to create a system greater than the sum of its parts has resulted in a powerful tool to research and industry. The BGS is in the process of developing a Low Cost GNSS system as a rugged "disposable" solution for monitoring the movement of a landslide, the flow velocity of a glacier, volcanic deformation, coastal evolution, or differential ground subsidence. In addition, UAVs can now be fitted with digital cameras, thermal detectors, multispectral cameras and LiDAR scanners to provide highly accurate data, with full-coverage 2D and 3D models.

Author Contributions: Conceptualization, methodology and investigation, L.J. and P.H.; writingoriginal draft preparation, L.J.; writing—review and editing, P.H.; visualization, L.J. All authors have read and agreed to the published version of the manuscript.

Funding: This research received no external funding.

Conflicts of Interest: The authors declare no conflict of interest.

\section{References}

1. Anon. ISO/TC 211 Geographic Information/Geomatics; ISO: Stockholm, Sweden, 1994. Available online: https://www.iso.org/ committee/54904.html (accessed on 30 July 2020).

2. Jones, L.D. Ground-Based Geomatic Surveys at the BGS: A Manual for Nasic Data Collection E Processing; British Geological Survey Open Report No. OR/15/057; British Geological Survey: London, UK, 2015.

3. Buckley, S.J.; Howell, J.; Enge, H.; Kurz, T. Terrestrial laser scanning in geology: Data acquisition, processing and accuracy considerations. J. Geol. Soc. 2008, 165, 625-638. [CrossRef]

4. Jones, L.D. Measuring our changing Earth. Planet Earth 2014, 28-29.

5. Jones, L.D.; Kirkham, M.; Hobbs, P.R.N. Ground-Based Geomatics for Geohazard Mapping, Modelling and Characterization; British Geological Open Report OR/20/019; British Geological Survey: London, UK, 2020.

6. Jordan, C.A.; Napier, B. Developing digital fieldwork technologies at the British Geological Survey. Geol. Soc. Lond. Spéc. Publ. 2015, 436, 219-229. [CrossRef]

7. Artese, S.; Zinno, R. TLS for Dynamic Measurement of the Elastic Line of Bridges. Appl. Sci. 2020, 10, 1182. [CrossRef]

8. Kamnik, R.; Perc, M.N.; Topolšek, D. Using the scanners and drone for comparison of point cloud accuracy at traffic accident analysis. Accid. Anal. Prev. 2020, 135, 105391. [CrossRef] [PubMed] 
9. Moskal, L.M.; Zheng, G. Retrieving Forest Inventory Variables with Terrestrial Laser Scanning (TLS) in Urban Heterogeneous Forest. Remote Sens. 2011, 4, 1-20. [CrossRef]

10. Pejanović Đurišić, M.; Tafa, Z.; Dimić, G.; Milutinovi, V. A survey of military applications of wireless sensor networks. In Proceedings of the Mediterranean Conference on Embedded Computing, Budva, Montenegro, 19-21 June 2012.

11. Jones, L.D. Ground-Based Geomatic Surveys: Specification for Terrestrial \& Mobile LiDAR Scanning; British Geological Survey Open Report No. OR/19/033; British Geological Survey: London, UK, 2019.

12. West, J.P.; Bowman, J.S. The Domestic Use of Drones: An Ethical Analysis of Surveillance Issues. Public Adm. Rev. 2016, 76, 649-659. [CrossRef]

13. Karakostas, I.; Mademlis, I.; Nikolaidis, N.; Pitas, I. UAV Cimematography Constraints Imposed by Visual Tracking. In Proceedings of the 25th IEEE International Conference on Image Processing (ICIP), Athens, Greece, 7-10 October 2018.

14. Nguyen, L.D.; Nguyen, K.K.; Kortun, A.; Duong, T.Q. Real-Time Deployment and Resource Allocation for Distributed UAV Systems in Disaster Relief. In Proceedings of the IEEE Workshop on Signal Processing Advances in Wireless Communications (SPAWC), Cannes, France, 2-5 July 2019.

15. Tapete, D.; Banks, V.; Jones, L.; Kirkham, M.; Garton, D. Contextualising archaeological models with geological, airborne and terrestrial LiDAR data: The Ice Age landscape in Farndon Fields, Nottinghamshire, UK. J. Archaeol. Sci. 2017, 81, 31-48. [CrossRef]

16. Glendell, M.; McShane, G.; Farrow, L.; James, M.R.; Quinton, J.; Anderson, K.; Evans, M.; Benaud, P.; Rawlins, B.; Morgan, D.; et al. Testing the utility of structure-from-motion photogrammetry reconstructions using small unmanned aerial vehicles and ground photography to estimate the extent of upland soil erosion. Earth Surf. Process. Landf. 2017, 42, 1860-1871. [CrossRef]

17. Giordan, D.; Adams, M.S.; Aicardi, I.; Alicandro, M.; Allasia, P.; Baldo, M.; De Berardinis, P.; Dominici, D.; Godone, D.; Hobbs, P.; et al. The use of unmanned aerial vehicles (UAVs) for engineering geology applications. Bull. Eng. Geol. Environ. 2020, 79, 3437-3481. [CrossRef]

18. Liu, X. Airborne LiDAR for DEM generation: Some critical issues. Prog. Phys. Geogr. Earth Environ. 2008, 32, 31-49. [CrossRef]

19. Larsen, C.F. Comparisons of Simultaneously Acquired Airborne Sfm Photogrammetry and LiDAR. In Proceedings of the American Geophysical Union, 2014 Fall Meeting, San Francisco, CA, USA, 15-19 December 2014.

20. Caduff, R.; Schlunegger, F.; Kos, A.; Wiesmann, A. A review of terrestrial radar interferometry for measuring surface change in the geosciences. Earth Surf. Process. Landf. 2015, 40, 208-228. [CrossRef]

21. Takada, Y.; Motono, G. Spatiotemporal behavior of a large-scale landslide at Mt. Onnebetsu-dake, Japan, detected by three L-band SAR satellites. Earth Planets Space 2020, 72, 1-18. [CrossRef]

22. Williams, R.D.; Lamy, M.L.; Maniatis, G.; Stott, E. Three-dimensional reconstruction of fluvial surface sedi-mentology and topography using personal mobile laser scanning. Earth Surf. Process. Landf. 2020, 45, 251-261. [CrossRef]

23. Toschi, I.; Rodriguezgonzalvez, P.; Remondino, F.; Minto, S.; Orlandini, S.; Fuller, A. Accuracy Evaluation of A Mobile Mapping System With Advanced Statistical Methods. ISPRS Int. Arch. Photogramm. Remote Sens. Spat. Inf. Sci. 2015, 5, 245-253. [CrossRef]

24. Hobbs, P.; Jones, L.D.; Kirkham, M.P.; Pennington, C.V.L.; Morgan, D.J.R.; Dashwood, C. Coastal landslide monitoring at Aldbrough, East Riding of Yorkshire, UK. Q. J. Eng. Geol. Hydrogeol. 2019, 53, 101-116. [CrossRef]

25. Hobbs, P.; Jones, L.; Kirkham, M.P.; Holyoake, S.J.; Pennington, C.V.L.; Dashwood, C.; Banks, V.J.; Reeves, H.J. Establishment of a coastal landslide observatory at Aldbrough, East Riding of Yorkshire, UK. Q. J. Eng. Geol. Hydrogeol. 2019, 53, 88-100. [CrossRef]

26. Anon. Overview of Icelandic Glaciers at the End of 2017. Newsletter. Newsletter. Icelandic Meteorological Office, Institute of Earth Sciences, University of Iceland and Southeast Iceland Nature Centre. 2018. Available online: https://en.vedur.is/media/ Eplican\%C3\%A1mskei\%C3\%B0/VAT/_newsletter/_2018/_06.pdf (accessed on 30 July 2020).

27. Philips, E.; Finlayson, A.; Jones, L. Fracturing, block-faulting and moulin development associated with progressive collapse and retreat of a polar maritime glacier: Virkisjökull-Falljökull, SE Iceland. J. Geophys. Res. Earth Surf. 2013, 118, 1545-1561. [CrossRef]

28. Philips, E.; Finlayson, A.; Bradwell, T.; Everest, J.; Jones, L. Structural evolution triggers a dynamic reduction in active glacier length during rapid retreat: Evidence from Falljokull, SE Iceland. J. Geophys. Res. Earth Surf. 2014, 119, 2194-2208. [CrossRef]

29. O' Dochartaigh, B.E.; MacDonald, A.M.; Black, A.R.; Everest, J.; Wilson, P.; Darling, W.G.; Jones, L.; Raines, M. Groundwatermeltwater interaction in proglacial aquifers amid rapid glacier retreat. Hydrol. Earth Syst. Sci. 2019, 23, 4527-4539. [CrossRef]

30. Anon, Zombie Glacier Surprises Scientists. Climate Central. 2014. Available online: https://www.climatecentral.org/news/ zombie-glacier-surprises-scientists-18209 (accessed on 30 July 2020).

31. Jones, L.D. Monitoring landslides in hazardous terrain using terrestrial LiDAR: An example from Montserrat. Q. J. Eng. Geol. Hydrogeol. 2006, 39, 371-373. [CrossRef]

32. Ryan, G.A.; Loughlin, S.C.; James, M.R.; Jones, L.D.; Calder, E.S.; Christopher, T.; Strutt, M.H.; Wadge, G. Growth of the lava dome and extrusion rates at Soufrière Hills Volcano, Montserrat, West Indies: 2005-2008. Geophys. Res. Lett. 2010, 37, $472-484$. [CrossRef]

33. Chambers, J.; Wilkinson, P.B.; Kuras, O.; Ford, J.R.; A Gunn, D.; I Meldrum, P.; Pennington, C.; Weller, A.; Hobbs, P.R.N.; Ogilvy, R. Three-dimensional geophysical anatomy of an active landslide in Lias Group mudrocks, Cleveland Basin, UK. Geomorphology 2011, 125, 472-484. [CrossRef] 